\title{
Cerámicas altomedievales en contextos rurales del centro y noroeste peninsular: secuencia cronotipológica, tecnología y regionalización productiva
}

\author{
Early medieval pottery in rural contexts from centre and \\ northwestern Iberia: tipological and chronological sequence, \\ technology and productive regionalization
}

\author{
Carlos Tejerizo-García \\ Universidad del País Vasco/Euskal Herriko Unibertsitatea
}

\section{RESUMEN}

En este trabajo se presentan los resultados de una detallada revisión de la cerámica doméstica de época altomedieval de una treintena de yacimientos del centro y noroeste peninsular. Mediante un análisis basado en las cadenas tecnológicooperativas se propone una secuenciación de los repertorios cerámicos entre los siglos $\mathrm{V}$ y VIII d. n. e. en torno a tres variables principales: tecnológica, formal y regional. De esta manera se propone una seriación cerámica de los conjuntos dividida en varias fases que permite una aproximación histórica en términos sociales y políticos a las sociedades altomedievales de este territorio.

\section{SUMMARY}

In this paper I present the main results of an extensive pottery analysis carried out on thirty early medieval rural contexts located in the centre and northwestern Iberia. Through an analysis based on the chaines opératoires a sequence of the pottery assemblages between the 5th and 8th century is presented. I will use three main variables: technology, form and regionalization. Thus, I will propose a pottery seriation in different phases which allows for a social and political historical approach of early medieval societies in this territory.

PALABRAS CLAVE: sociedades altomedievales; meseta norte; poblamiento; cadenas tecnológico-operativas; estratigrafía.

KEY WORDS: early medieval societies; North Iberia; settlement pattern; chaînes opératoires; stratigraphy.

${ }^{1}$ carlosteje@gmail.com / ORCID iD: https://orcid.org/00000001-9479-2720
CÓMO CITAR ESTE ARTÍCULO / CITATION: TejerizoGarcía, C. 2020: "Cerámicas altomedievales en contextos rurales del centro y noroeste peninsular: secuencia cronotipológica, tecnología y regionalización productiva", Archivo Español de Arqueología 93, 275-301. https://doi. org/10.3989/aespa.093.020.014

\section{INTRODUCCIÓN}

La cerámica de época altomedieval ha constituido tradicionalmente un terreno pantanoso para la Arqueología en el centro y noroeste peninsular ${ }^{2}$. El final de los ciclos de producción del período tardoimperial, especialmente el de la sigillata tardía, generaba significativas limitaciones para la investigación, incapaces de atenerse a cronotipologías sólidas que permitieran profundizar en la propia historia de las sociedades que las produjeron. Dichos obstáculos se hacían más evidentes al confrontar el mundo rural altomedieval, todavía menos conocido hasta muy recientemente. Este panorama ha cambiado de forma radical en las últimas dos décadas con la excavación y publicación de un elevado número de contextos rurales que han permitido dar un salto cuantitativo y cualitativo a la comprensión de la cerámica altome-

\footnotetext{
${ }^{2}$ Esta afirmación se refiere específicamente a este ámbito geográfico, cuya historiografía se diferencia de otros entornos, con especial referencia al sureste o al noreste peninsular, en los que este problema fue confrontado no solo antes, sino con herramientas metodológicas distintas (Alba y Gutiérrez Lloret 2008; Amorós Ruiz 2018; Caballero Zoreda et alii 2003; Comas i Solà et alii 1997).
}

Copyright: ( 2020 CSIC. Este es un artículo de acceso abierto distribuido bajo los términos de una licencia de uso y distribución Creative Commons Reconocimiento 4.0 Internacional (CC-by 4.0). 
dieval en los ámbitos rurales, tanto en sus aspectos cronotipológicos, como en sus aspectos tecnológicos y sociales (Ariño et alii 2005; Dahí Elena 2012; Vigil-Escalera y Quirós Castillo 2016). En el caso específico del centro y del noroeste peninsular este panorama tuvo un importante impulso, sobre todo tras la publicación del fundamental trabajo de 2003 que compilaba los mejores materiales disponibles en aquel momento para afrontar la secuencia de la cerámica entre los siglos V y VIII d. n. e. en ámbitos rurales (Larrén et alii 2003).

Desde entonces, la proliferación de intervenciones en el marco de la arqueología comercial ha proporcionado una ingente cantidad de datos (Tejerizo García 2017a). Sin embargo, y aún a pesar de todas las intervenciones realizadas y los datos disponibles, estos conjuntos cerámicos no han sido todavía objeto de un "ensayo de sistematización" como el que se propuso en 2003 que permita proponer una secuenciación sólida. Si bien el número de excavaciones y de material efectivamente disponible es más que suficiente, este se encuentra disperso en informes inéditos de diversa calidad, publicaciones parciales y, sobre todo, en los almacenes de los museos, esperando para ser revisados. Esta situación no es consecuencia, por tanto, de una falta de voluntad o de base empírica sino, fundamentalmente, de la falta de medios para abordar un estudio de esta magnitud. En el contexto de la realización de una tesis doctoral y de un contrato postdoctoral, se tuvo la oportunidad de revisar un significativo conjunto de cerámicas provenientes de una importante variedad de yacimientos rurales datados entre los siglos V y VIII d. n. e. que constituye la base del presente trabajo ${ }^{4}$.

El objetivo principal del presente trabajo es sistematizar los principales resultados de ese análisis. En primer lugar, se introducirán y contextualizarán los yacimientos analizados, así como la metodología utilizada y los fundamentos de la cronología propuesta para estos sitios. La segunda parte del trabajo expondrá el análisis de la cerámica desde tres puntos de vista: el tecnológico, profundizando en diversos aspectos relacionados con la cadena tecnológico-operativa de estas cerámicas; el cronotipológico, proponiendo una secuencia formal de la cerámica altomedieval

${ }^{3}$ La historiografía de los estudios cerámicos postromanos en el centro peninsular ha sido objeto de diversas publicaciones a las que remitimos. Para una reciente y completa revisión ver (Aranda González 2014).

${ }^{4}$ Se establece el siglo VIII d. n. e. como el límite del estudio dados los profundos cambios que se producen durante esa centuria que afectan de manera muy intensa a la cerámica y que requerirían de estudios y análisis particulares (Serrano Herrero et alii 2016). en los ámbitos rurales del centro y noroeste peninsular; y el geográfico, con un primer acercamiento a las potenciales variedades territoriales. Finalmente, se realizarán algunas consideraciones, más en términos de preguntas y agenda de trabajo, que puedan orientar los estudios de cara al futuro.

\section{CONTEXTOS ANALIZADOS, METODOLOGÍA Y PROPUESTA CRONOLÓGICA GENERAL}

El conjunto de yacimientos analizados para el presente trabajo es de treinta (Figs. 1 y 2).

Salvo los yacimientos de Castro Ventosa y Viladonga, incluidos por su interés en términos comparativos, el resto se ubican en la franja central de la cuenca del río Duero. Prácticamente todos los yacimientos provienen de excavaciones de urgencia vinculados a la construcción de autovías y, además, excavados por diferentes profesionales y empresas, con procedimientos y criterios metodológicos variados (Tejerizo García 2017a). Un aspecto clave es que todas estas intervenciones tienen una estratigrafía definida, lo que ha permitido contextualizar con un alto grado de coherencia el material cerámico.

Igualmente, todos ellos son contextos rurales datados entre los siglos V y VIII d. n. e. y responden a tres principales tipos. En primer lugar, se consideran asentamientos rurales vinculados espacialmente a antiguas villas tardoimperiales, lo que en otros trabajos se denominaron como "aldeas de primera generación" (Tejerizo García 2016b, 2017a). En segundo lugar, se ha tenido en cuenta un pequeño conjunto de asentamientos fortificados, caracterizados por su ubicación en un entorno de altura relativa y con presencia de un recinto amurallado (Gutiérrez González 2014). Finalmente, se diferencia entre asentamientos rurales abiertos tipo aldeas y granjas, tal y como fueron definidas por autores como A. Vigil-Escalera o J.A. Quirós Castillo (Quirós Castillo 2013; Vigil-Escalera 2007b). Ambas categorías de poblamiento se definen como resultado de la actividad de un número restringido de unidades domésticas (granjas) o por la de un grupo plurifamiliar o comunidad (aldea).

Cabe reseñar, como aspecto relevante a la hora de tener en cuenta los análisis y resultados aquí presentados, que prácticamente en todos los yacimientos, salvo excepciones como Viladonga, Castro Ventosa, Navasangil o El Ventorro, se realizó una selección previa por parte de los excavadores de la cerámica antes de ser inventariada y depositada en los museos, lo que conlleva algunas limitaciones, como la posible sobrerrepresentación de algunas producciones sobre 


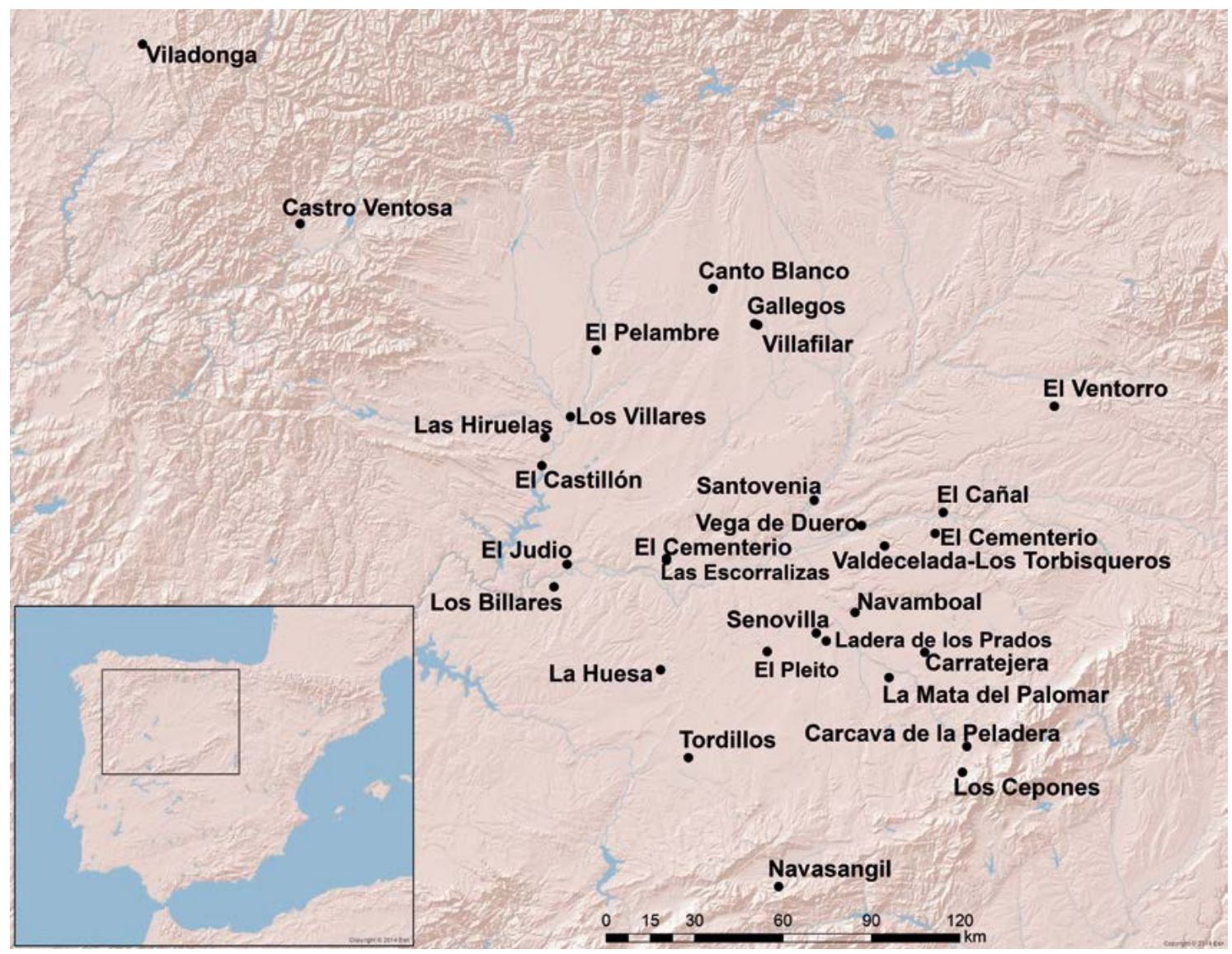

Figura 1. Mapa de distribución de los yacimientos analizados (elaboración propia).

otras $^{5}$. Sin embargo, el alto número de contextos y de material revisado, así como su comparación con otros contextos arqueológicos de ámbitos geográficos cercanos, permite asegurar una alta fiabilidad a los resultados aquí obtenidos.

En todos los yacimientos analizados, salvo en el yacimiento de El Castillón -incluido por su relevancia para el análisis de la cerámica altomedieval en la cuenca del Duero a partir de sus publicaciones principales (Sastre Blanco et alii 2014; Sastre Blanco et alii 2018)se siguió la misma metodología de trabajo. Partiendo de los principios de la Antropología de la Tecnología desarrollada por P. Lemmonier (Lemonnier 1992, 1993; Marín Suárez 2012), se revisaron todos los fragmentos cerámicos de cada unidad estratigráfica, diferenciando las cadenas tecnológico-productivas (CTO) presentes, atendiendo tanto a sus características tecnológicas - principalmente las variables de sistema de

\footnotetext{
5 Para una discusión específica sobre este aspecto y las limitaciones que conlleva, véase Tejerizo García 2016a.
}

modelado, grado de depuración ${ }^{6}$, tipo de inclusiones y tipo de cocción-como morfológicas - principalmente formas y decoraciones-. Cada una de estas CTO fue cuantificada en número de fragmentos y peso, de forma que el resultado final es una estimación de su incidencia relativa en cada unidad estratigráfica y en el yacimiento en su conjunto.

Siguiendo esta metodología, se han analizado para el presente trabajo un total de 20582 fragmentos cerámicos, lo que supone el estudio cuantitativo más amplio realizado para la cerámica de este período en la meseta norte ${ }^{7}$.

\footnotetext{
${ }^{6}$ El criterio del grado de depuración de las cerámicas es, a falta de un consenso general y de estudios arqueométricos, relativamente subjetivo. De hecho, este tipo de criterios suele depender del propio contexto cerámico en estudio, no siendo igual para contextos prehistóricos que para cerámicas de época romana. Para los análisis realizados en este trabajo hemos considerado tres niveles de depuración: bajo, con inclusiones superiores a $2 \mathrm{~mm}$; medio, con inclusiones entre 1-2 mm; y alto, con inclusiones menores a $1 \mathrm{~mm}$.

7 Como punto de comparación, se debe mencionar que en el
} 


\begin{tabular}{|c|c|c|c|c|c|c|c|}
\hline YACIMIENTO & LUGAR & $\begin{array}{l}\text { CRONOLOGÍA } \\
\text { PROPUESTA }\end{array}$ & $\begin{array}{c}\text { AÑO DE } \\
\text { EXCAVACIÓN }\end{array}$ & $\begin{array}{c}\text { TIPO DE } \\
\text { ASENTAMIENTO }\end{array}$ & $\begin{array}{c}\text { EXTENSIÓN } \\
\text { EXCAVADA } \\
\left(\mathrm{en} \mathrm{m}^{2}\right)\end{array}$ & $\begin{array}{l}\text { NÚMERO DE } \\
\text { CERÁMICAS } \\
\text { ANALIZADAS }\end{array}$ & BIBLIOGRAFÍA \\
\hline Villafilar & Palencia & Fines IV-med. V & 2010 & $\begin{array}{l}\text { Villa tardorromana/ } \\
\text { aldea }\end{array}$ & 14800 & 510 & (Strato, 2010b) \\
\hline Carratejera & $\begin{array}{l}\text { Navalmanzano, } \\
\text { Segovia }\end{array}$ & $1 / 3 \mathrm{~V}-3 / 4 \mathrm{~V}$ & 2003 Y 2007 & $\begin{array}{l}\text { Entorno villa } \\
\text { tardorromana }\end{array}$ & 12500 & 1083 & $\begin{array}{c}\text { (2barqueologia, } \\
\text { 2007-2008; Strato, } \\
\text { 2003) }\end{array}$ \\
\hline Los Villares & $\begin{array}{l}\text { Villanueva de } \\
\text { Azoague, } \\
\text { Zamora }\end{array}$ & Fines IV-3/4 V & 1985 y 1999 & $\begin{array}{l}\text { ¿Aldea de primera } \\
\text { generación? }\end{array}$ & 51,6 & & $\begin{array}{l}\text { (López Rodríguez y } \\
\text { Regueras Grande, } \\
\text { 1987; Strato, 1999b) }\end{array}$ \\
\hline El Judío & Zamora & $2 / 2 \mathrm{~V}$ & 2005 & $\begin{array}{l}\text { Aldea de primera } \\
\text { generación }\end{array}$ & 5800 & 279 & (Strato, 2005) \\
\hline El Pelambre & $\begin{array}{l}\text { Villaornate- } \\
\text { Castro, León }\end{array}$ & Fin V-Med. VI & 2006 & Granja & 11000 & 81 & $\begin{array}{c}\text { (González } \\
\text { Fernández, 2009) }\end{array}$ \\
\hline Vega de Duero & Valladolid & Med. V-Fin V & 1992 & Granja/aldea & 28,5 & 469 & $\begin{array}{c}\text { (Bellido Blanco, } \\
\text { 1997) }\end{array}$ \\
\hline Castro Ventosa & Cacabelos, León & Inicios V-inicios VI & $\begin{array}{l}\text { Med. 70s, Fines } \\
80,2001,2004, \\
2006\end{array}$ & $\begin{array}{l}\text { Asentamiento } \\
\text { fortificado }\end{array}$ & 45,43 & 2263 & $\begin{array}{l}\text { (Balboa De Paz et } \\
\text { al., 2003; Strato, } \\
\text { 2001, 2004b) }\end{array}$ \\
\hline El Castillón & $\begin{array}{l}\text { Santa Eulalia de } \\
\text { Tábara, Zamora }\end{array}$ & Fines s.IV-s.VI & $2007-2018$ & $\begin{array}{l}\text { Asentamiento } \\
\text { fortificado }\end{array}$ & - & - & $\begin{array}{c}\text { (Sastre Blanco et al., } \\
\text { 2014) }\end{array}$ \\
\hline Viladonga & $\begin{array}{l}\text { Castro de Rei, } \\
\text { Lugo }\end{array}$ & Fines s.IV-med. VI & $\begin{array}{l}\text { 60s hasta } \\
\text { actualidad }\end{array}$ & $\begin{array}{l}\text { Asentamiento } \\
\text { fortificado }\end{array}$ & 6476 & 5751 & $\begin{array}{c}\text { (Arias Vilas et al., } \\
\text { 2013) }\end{array}$ \\
\hline Navasangil & $\begin{array}{l}\text { Solosancho, } \\
\text { Ávila }\end{array}$ & Med V-Med. VI & 70s, fines 90 & $\begin{array}{l}\text { Asentamiento } \\
\text { fortificado }\end{array}$ & 800 & 475 & $\begin{array}{c}\text { (Caballero Arribas, } \\
\text { 2000, 2003; Larrén, } \\
\text { 1989) }\end{array}$ \\
\hline $\begin{array}{l}\text { Cárcava de la } \\
\text { Peladera }\end{array}$ & $\begin{array}{l}\text { Hontoria, } \\
\text { Segovia }\end{array}$ & Fin V-Med. VI & 1999 y 2002 & Granja & 2013 & 1418 & (Quirós, 2013) \\
\hline Gallegos & $\begin{array}{l}\text { Pozo de Urama, } \\
\text { Palencia }\end{array}$ & Fin V-VI & 2010 & Aldea & 6700 & 108 & (Strato, 2010a) \\
\hline $\begin{array}{l}\text { El Cementerio- } \\
\text { Camino de } \\
\text { Pedrosa }\end{array}$ & $\begin{array}{l}\text { Morales de Toro, } \\
\text { Zamora }\end{array}$ & Fin V-med. VI & 1996 & Aldea & 55,5 & 138 & (Strato, 1996) \\
\hline El Cementerio & $\begin{array}{l}\text { Langayo, } \\
\text { Valladolid }\end{array}$ & VI-med. VII & 1997 & Aldea & 416 & 170 & (Strato, 1997a) \\
\hline $\begin{array}{l}\text { Ladera de los } \\
\text { Prados }\end{array}$ & $\begin{array}{l}\text { Aguasal, } \\
\text { Valladolid }\end{array}$ & VI-VII & 2002 & Aldea & 7077 & 1009 & (Quirós, 2013) \\
\hline $\begin{array}{l}\text { Las Escorralizas- } \\
\text { Camino de } \\
\text { Quiñones }\end{array}$ & $\begin{array}{l}\text { Morales de Toro, } \\
\text { Zamora }\end{array}$ & VI-VII & 1996 & Aldea & 55 & 237 & (Strato, 1996) \\
\hline Canto Blanco & $\begin{array}{l}\text { Calzada de Coto, } \\
\text { León }\end{array}$ & $\begin{array}{l}\text { VI-VIII (hasta s. } \\
\text { XI/XII) }\end{array}$ & 2009 & Granja & 10557 & 267 & (Quirós, 2013) \\
\hline Senovilla & $\begin{array}{l}\text { Olmedo, } \\
\text { Valladolid }\end{array}$ & VI-VIII & 2007 & Aldea & 7600 & 596 & (Strato, 2007a) \\
\hline Santovenia & Valladolid & VI-VIII & $2008-2009$ & Aldea & 3423 & 309 & (Strato, 2011) \\
\hline El Cañal & $\begin{array}{l}\text { Pesquera de } \\
\text { Duero, } \\
\text { Valladolid }\end{array}$ & VI-VIII & 2008 & Aldea & 1568,5 & 58 & (Strato, 2008) \\
\hline Tordillos & Salamanca & Med. VI-VII & $2006-2007$ & Aldea & 8460 & 78 & (Strato, 2006) \\
\hline $\begin{array}{l}\text { El Pleito-La } \\
\text { Casilla }\end{array}$ & $\begin{array}{c}\text { Rubí de } \\
\text { Bracamonte, } \\
\text { Valladolid }\end{array}$ & Med. VI-VII & 1998 & Granja/aldea & 80 & 38 & $\begin{array}{c}\text { (Strato, 1998; } \\
\text { Wattenberg, 1990) }\end{array}$ \\
\hline Los Billares & Zamora & Med. VI-VII & 2000 & Granja/aldea & 28,25 & 52 & (Strato, 2000) \\
\hline $\begin{array}{l}\text { La Mata del } \\
\text { Palomar }\end{array}$ & Nieva, Segovia & Med. VI-VIII & 2002 & Aldea & 5588 & 2299 & (Quirós, 2013) \\
\hline Navamboal & Íscar, Valladolid & Fin VI-VIII & 2004 & Aldea & 4000 & 349 & (Quirós, 2013) \\
\hline
\end{tabular}




\begin{tabular}{|c|c|c|c|c|c|c|c|}
\hline YACIMIENTO & LUGAR & $\begin{array}{l}\text { CRONOLOGÍA } \\
\text { PROPUESTA }\end{array}$ & $\begin{array}{c}\text { Ã̃̃ DE } \\
\text { EXCAVACIÓN }\end{array}$ & $\begin{array}{c}\text { TIPO DE } \\
\text { ASENTAMIENTO }\end{array}$ & $\begin{array}{c}\text { EXTENSIÓN } \\
\text { EXCAVADA } \\
\left(\mathrm{en} \mathrm{m}^{2}\right)\end{array}$ & $\begin{array}{l}\text { NÚMERO DE } \\
\text { CERÁMICAS } \\
\text { ANALIZADAS }\end{array}$ & BIBLIOGRAFÍA \\
\hline $\begin{array}{l}\text { Valdecelada-Los } \\
\text { Torbisqueros }\end{array}$ & $\begin{array}{c}\text { Montemayor de } \\
\text { Pililla, Valladolid }\end{array}$ & Med. VI-_VIII? & 1997 & Granja/aldea & 55 & 78 & (Strato, 1997b) \\
\hline El Ventorro & $\begin{array}{c}\text { Aranda de } \\
\text { Duero, Burgos }\end{array}$ & VII-VIII & $2002-2003$ & Aldea & 3520 & 1098 & $\begin{array}{c}\text { (Aratikos, 2002; } \\
\text { Bores Ureta, 2004) }\end{array}$ \\
\hline Los Cepones & La Losa, Segovia & VII-VIII & 2001-2002 & Granja & 725 & 492 & (Strato, 2002c) \\
\hline La Huesa & Cañizal, Zamora & VII-VIII & $\begin{array}{c}1983,1994 \mathrm{y} \\
1997\end{array}$ & Aldea & 705,5 & 726 & $\begin{array}{c}\text { (Fernández } \\
\text { González, 1985; } \\
\text { Nuño González, } \\
\text { 2003; Presas Vias et } \\
\text { al., 1994) }\end{array}$ \\
\hline Las Hiruelas & $\begin{array}{l}\text { Burganes de } \\
\text { Valverde, } \\
\text { Zamora }\end{array}$ & VIII-XI & 2007 & Granja/aldea & 268 & 76 & (Strato, 2007b) \\
\hline
\end{tabular}

Figura 2. Principales características de los yacimientos objetos de estudio (elaboración propia).

Un tema esencial antes de abordar el análisis detallado de estos resultados es la datación de los yacimientos y, en consecuencia, de los contextos cerámicos. La propuesta de datación de cada contexto que se expone en la figura 3 es el resultado de un proceso inductivo y heurístico a partir de la puesta en común de los resultados obtenidos del análisis cerámico particular de cada yacimiento. Cada uno de los yacimientos -y sus contextos cerámicos-fue datado a partir de la revisión crítica y exhaustiva del material cerámico teniendo en cuenta la propuesta inicial de sus excavadores, la presencia -en su caso- de dataciones absolutas (Figs. 3 y 4), así como los avances historiográficos disponibles. Una vez generada una propuesta de datación por cada yacimiento, se combinó y comparó toda la información disponible de forma que se pudo proponer una secuencia relativa de los sitios en conjunto que permite diferenciar contextos más antiguos de otros más modernos. Así, por ejemplo, se entiende que el contexto de Carratejera es más antiguo que el de El Pelambre, que comparte cierta sincronía con La Cárcava de la Peladera y, a su vez, ambos son más antiguos que La Mata del Palomar, y así sucesivamente. Evidentemente, esto solo resuelve una parte del problema, dado que no logra realmente situar cada yacimiento dentro de unas coordenadas históricas concretas y absolutas, pero sí permite ordenarlos secuencialmente. De esta manera, y con todas las evidentes precauciones, se ha podido realizar un acercamiento en términos diacrónicos a estos contextos y, por consiguiente, a una propuesta de secuencia cronotipológica de la cerámica asociada.

Con este aparato crítico, realizaremos en los siguientes apartados distintas consideraciones que ata-

estudio de 2003 se analizaron unos 2000 fragmentos aproximadamente (Larrén et alii 2003). ñen a los aspectos tecnológicos, formales y de regionalización productiva de la cerámica de la cuenca del Duero, atendiendo a su dimensión diacrónica y a los cambios detectados en los mismos.

\section{ASPECTOS TECNOLÓGICOS: PROPUESTA HISTÓRICA DEL DESARROLLO DE LAS PRODUCCIONES CERÁMICAS ALTOMEDIEVALES EN LA CUENCA DEL DUERO}

Partiendo de la metodología expuesta previamente se han podido distinguir las siguientes cadenas tecnológicas en el repertorio cerámico de los siglos V-VIII d. n. e. (Fig. 5). El resultado de las cuantificaciones realizadas en cada yacimiento se resume en la Figura $6 .{ }^{8}$

En los siguientes apartados se realizará un análisis en términos cronológicos de los cambios producidos en las producciones cerámicas, distinguiendo dos grandes períodos: uno correspondiente a la quinta centuria y la mitad del s. VI d. n. e. y otro entre este momento y mediados de la octava centuria.

\section{I. LAS PRODUCCIONES CERÁMICAS DEL SIGLO V-MEDIADOS DEL SIGLO VI EN LA CUENCA DEL DUERo}

La quinta centuria supone un momento de importante ruptura en amplios sectores y escalas en el centro y norte peninsular (Tejerizo García 2016b; Vigil-Es-

\footnotetext{
${ }^{8}$ En esta tabla se ha incluido una categoría genérica para la cerámica de época prerromana (PREH) con el objetivo de representar toda la cerámica presente en los contextos, así como la potencial residualidad.
} 


\begin{tabular}{|c|c|c|c|c|c|c|c|c|c|}
\hline YACIMIENTO & LUGAR & CONTEXTO & TIPO & MATERIAL & DATACIÓN & $\begin{array}{c}\text { CALIBRACIÓN } \\
\text { TL }\end{array}$ & 2 SIGMA & $\begin{array}{c}\text { NÚMERO DE } \\
\text { REF. }\end{array}$ & BIBLIOGRAFÍA \\
\hline El Pelambre & $\begin{array}{l}\text { Villaornate, } \\
\text { León }\end{array}$ & Hoyo 33 & $\mathrm{C} 14$ & Hueso animal & $1490 \pm 35$ & - & 427-651CalAD & Ua-33191 & $\begin{array}{c}\text { GONZÁLEZ Y } \\
\text { PÉREZ, } 2009\end{array}$ \\
\hline El Pelambre & $\begin{array}{l}\text { Villaornate, } \\
\text { León }\end{array}$ & Hoyo 55 & $\mathrm{C} 14$ & Hueso animal & $1564 \pm 45$ & - & $\begin{array}{c}347-370 \mathrm{calAD} \\
(0,4 \%) \\
378-637 \mathrm{cal} \mathrm{AD} \\
(99.3 \%)\end{array}$ & CSIC-2109 & $\begin{array}{c}\text { GONZÁLEZY } \\
\text { PÉREZ, } 2009\end{array}$ \\
\hline $\begin{array}{l}\text { La Mata del } \\
\text { Palomar }\end{array}$ & Nieva, Segovia & UE 442 & $\mathrm{C} 14$ & $\begin{array}{l}\text { Hueso humano; } \\
\text { fémur derecho }\end{array}$ & $1275 \pm 45$ & - & 644-894calAD & Ua 20081 & STRATO, 2002 \\
\hline $\begin{array}{l}\text { La Mata del } \\
\text { Palomar }\end{array}$ & Nieva, Segovia & UE 362 & $\mathrm{TL}$ & $\begin{array}{l}\text { Ladrillos. Pilar } \\
\text { cámara de } \\
\text { combustión }\end{array}$ & $1212 \pm 101$ & VII-IX & & Mad-3073 & STRATO, 2002 \\
\hline $\begin{array}{c}\text { La Cárcava de la } \\
\text { Peladera }\end{array}$ & $\begin{array}{c}\text { Hontoria, } \\
\text { Segovia }\end{array}$ & UE 38 (hoyo 8) & $\mathrm{Cl} 4$ & Carbón vegetal & $1500 \pm 50 \mathrm{BP}$ & - & 404-660 calAD & $\begin{array}{l}\text { PELADERA-2, } \\
\text { Beta Analytic }\end{array}$ & STRATO, 1999a \\
\hline $\begin{array}{l}\text { La Cárcava de la } \\
\text { Peladera }\end{array}$ & $\begin{array}{c}\text { Hontoria, } \\
\text { Segovia }\end{array}$ & $\begin{array}{l}\text { UE } 20 \text { (cabaña } \\
\text { 1) }\end{array}$ & $\mathrm{C} 14$ & Carbón vegetal & $1740 \pm 60 \mathrm{BP}$ & - & $\begin{array}{c}75-474 \mathrm{calAD} \\
(98,8 \%) \\
486-535 \mathrm{calAD} \\
(0,9 \%)\end{array}$ & $\begin{array}{c}\text { PELADERA-1, } \\
\text { Beta Analytic }\end{array}$ & STRATO, 1999 \\
\hline $\begin{array}{l}\text { La Cárcava de la } \\
\text { Peladera }\end{array}$ & $\begin{array}{c}\text { Hontoria, } \\
\text { Segovia }\end{array}$ & UE 42 (hoyo 6) & $\mathrm{Cl} 4$ & Carbón vegetal & $1720 \pm 60 \mathrm{BP}$ & - & $\begin{array}{c}86-109 \mathrm{calAD} \\
(0,3 \%) \\
117-540 \mathrm{calAD} \\
(99,4 \%)\end{array}$ & $\begin{array}{l}\text { PELADERA-3, } \\
\text { Beta Analytic }\end{array}$ & STRATO, 1999 \\
\hline $\begin{array}{c}\text { Alto del Mural/ } \\
\text { Camino de los } \\
\text { Aguanares }\end{array}$ & Cogollos, Burgos & AM-03 & $\mathrm{C} 14$ & Fauna & $1549 \pm 35$ & - & 397-618calAD & Ua-38110 & $\begin{array}{c}\text { ALONSO } \\
\text { FERNÁNDEZ, C., } \\
\text { \& JIMÉNEZ } \\
\text { ECHEVARRÍA, J. } \\
\text { (2010) }\end{array}$ \\
\hline $\begin{array}{l}\text { Alto del Mural/ } \\
\text { Camino de los } \\
\text { Aguanares }\end{array}$ & Cogollos, Burgos & AM-27 & $\mathrm{C} 14$ & Fauna & $1568 \pm 30$ & - & 397-593calAD & Ua-38111 & $\begin{array}{c}\text { ALONSO } \\
\text { FERNÁNDEZ, C., } \\
\text { \& JIMÉNEZ } \\
\text { ECHEVARRÍA, J. } \\
\text { (2010) }\end{array}$ \\
\hline $\begin{array}{l}\text { Alto del Mural/ } \\
\text { Camino de } \\
\text { Aguanares }\end{array}$ & Cogollos, Burgos & AM-28 & $\mathrm{C} 14$ & Fauna & $1613 \pm 33$ & - & $334-563 \mathrm{calAD}$ & Ua-38112 & $\begin{array}{c}\text { ALONSO } \\
\text { FERNÁNDEZ, C., } \\
\text { \& JIMÉNEZ } \\
\text { ECHEVARRÍA, J. } \\
\text { (2010) }\end{array}$ \\
\hline $\begin{array}{l}\text { El Cristo de San } \\
\text { Esteban }\end{array}$ & $\begin{array}{c}\text { Muelas de Pan, } \\
\text { Zamora }\end{array}$ & UE 50 & $\mathrm{Cl} 4$ & $\begin{array}{l}\text { Poste de } \\
\text { madera }\end{array}$ & $1899 \pm 29$ & - & 9-234calAD & CSIC-1886 & $\begin{array}{c}\text { ALONSO Y NUÑO } \\
2014\end{array}$ \\
\hline $\begin{array}{l}\text { El Cristo de San } \\
\text { Esteban }\end{array}$ & $\begin{array}{c}\text { Muelas de Pan, } \\
\text { Zamora }\end{array}$ & UE 50 & $\mathrm{Cl} 4$ & $\begin{array}{c}\text { Granos de } \\
\text { cereal }\end{array}$ & $1440 \pm 28$ & - & 546-661calAD & CSIC-1885 & $\begin{array}{l}\text { DOMÍNGUEZY } \\
\text { NUÑO, } 2014\end{array}$ \\
\hline El Cuquero & $\begin{array}{l}\text { Villanueva del } \\
\text { Conde, } \\
\text { Salamanca }\end{array}$ & - & $\mathrm{C} 14$ & Carbón & $1480 \pm 120 \mathrm{BP}$ & - & 133-898calAD & UBAR-809 & ARIÑO, 2004- 2005 \\
\hline Saelices el Chico & $\begin{array}{c}\text { Saelices el Chico, } \\
\text { Salamanca }\end{array}$ & UE 9 & $\mathrm{Cl} 4$ & & $1530 \pm 35 \mathrm{BP}$ & - & 411-640calAD & UBAR-895 & DAHI, 2012 \\
\hline $\begin{array}{c}\text { La Armuña } \\
\text { (columna } \\
\text { polínica) }\end{array}$ & $\begin{array}{c}\text { Prado de la Vega, } \\
\text { Salamanca }\end{array}$ & - & $\mathrm{C} 14$ & & $1170 \pm 95 \mathrm{BP}$ & - & 616-1156calAD & - & $\begin{array}{c}\text { ARIÑO, RIERA Y } \\
\text { HERNÁNDEZ, } \\
2002\end{array}$ \\
\hline Gallegos & $\begin{array}{l}\text { Pozo de Urama, } \\
\text { Palencia }\end{array}$ & Hoyo 126. & $\mathrm{TL}$ & Adobe en silo & $1623 \pm 109 \mathrm{BP}$ & $387 \pm 109(278-496)$ & & MADN-5801BIN & STRATO, 2010 \\
\hline Fuenteungrillo & $\begin{array}{l}\text { Villalba de los } \\
\text { Alcores, } \\
\text { Valladolid }\end{array}$ & - & $\mathrm{C} 14$ & - & $1165 \pm 30 \mathrm{BP}$ & - & $\begin{array}{c}721-741 \mathrm{calAD} \\
(0,7 \%) \\
766-985 \mathrm{cal} A \mathrm{AD} \\
(99 \%)\end{array}$ & - & QUIRÓS, 2007 \\
\hline Tedeja & $\begin{array}{l}\text { Trespaderne, } \\
\text { Burgos }\end{array}$ & Cubo 1 & $\mathrm{C} 14$ & $\begin{array}{c}\text { Material } \\
\text { orgánico; } \\
\text { Material } \\
\text { constructivo }\end{array}$ & $1300 \pm 100 \mathrm{BP}$ & - & $\begin{array}{c}428-498 \mathrm{calAD} \\
(1 \%) \\
505-1019 \mathrm{calAD} \\
(98,7)\end{array}$ & - & $\begin{array}{c}\text { PALOMINO, } \\
\text { NEGREDO Y } \\
\text { BOHIGAS, } 2012\end{array}$ \\
\hline
\end{tabular}




\begin{tabular}{|c|c|c|c|c|c|c|c|c|c|}
\hline YACIMIENTO & LUGAR & CONTEXTO & TIPO & MATERIAL & DATACIÓN & $\begin{array}{c}\text { CALIBRACIÓN } \\
\text { TL }\end{array}$ & 2SIGMA & $\begin{array}{c}\text { NÚMERO DE } \\
\text { REF. }\end{array}$ & BIBLIOGRAFÍA \\
\hline Tedeja & $\begin{array}{c}\text { Trespaderne, } \\
\text { Burgos }\end{array}$ & Cubo 5 & $\mathrm{Cl} 4$ & $\begin{array}{c}\text { Material } \\
\text { orgánico; } \\
\text { Material } \\
\text { constructivo }\end{array}$ & $1510 \pm 70$ & - & $329-686$ calAD & - & $\begin{array}{c}\text { PALOMINO, } \\
\text { NEGREDOY } \\
\text { BOHIGAS, 2012 }\end{array}$ \\
\hline Carratejera & $\begin{array}{c}\text { Navalmanzano, } \\
\text { Segovia }\end{array}$ & $\begin{array}{c}\text { Horno } \\
\text { estructura 201 }\end{array}$ & $\mathrm{TL}$ & $\begin{array}{c}\text { Fragmento de } \\
\text { pared del horno }\end{array}$ & $1738 \pm 139 \mathrm{BP}$ & $265 \pm 139$ & & $\begin{array}{c}\text { MAD-3531 } \\
\text { Navalmanzano-2 }\end{array}$ & STRATO, 2003 \\
\hline Villafilar & $\begin{array}{c}\text { Cisneros, } \\
\text { Palencia }\end{array}$ & $\begin{array}{c}\text { Fragmento de } \\
\text { horno }\end{array}$ & $\mathrm{TL}$ & $\begin{array}{c}\text { Fragmento de } \\
\text { pared }\end{array}$ & $1603 \pm 109 \mathrm{BP}$ & $407 \pm 109$ & & MADN-5784BIN & STRATO, 2010 \\
\hline
\end{tabular}

Figura 3. Principales características de las dataciones absolutas recogidas para el ámbito de la cuenta del Duero (elaboración propia).

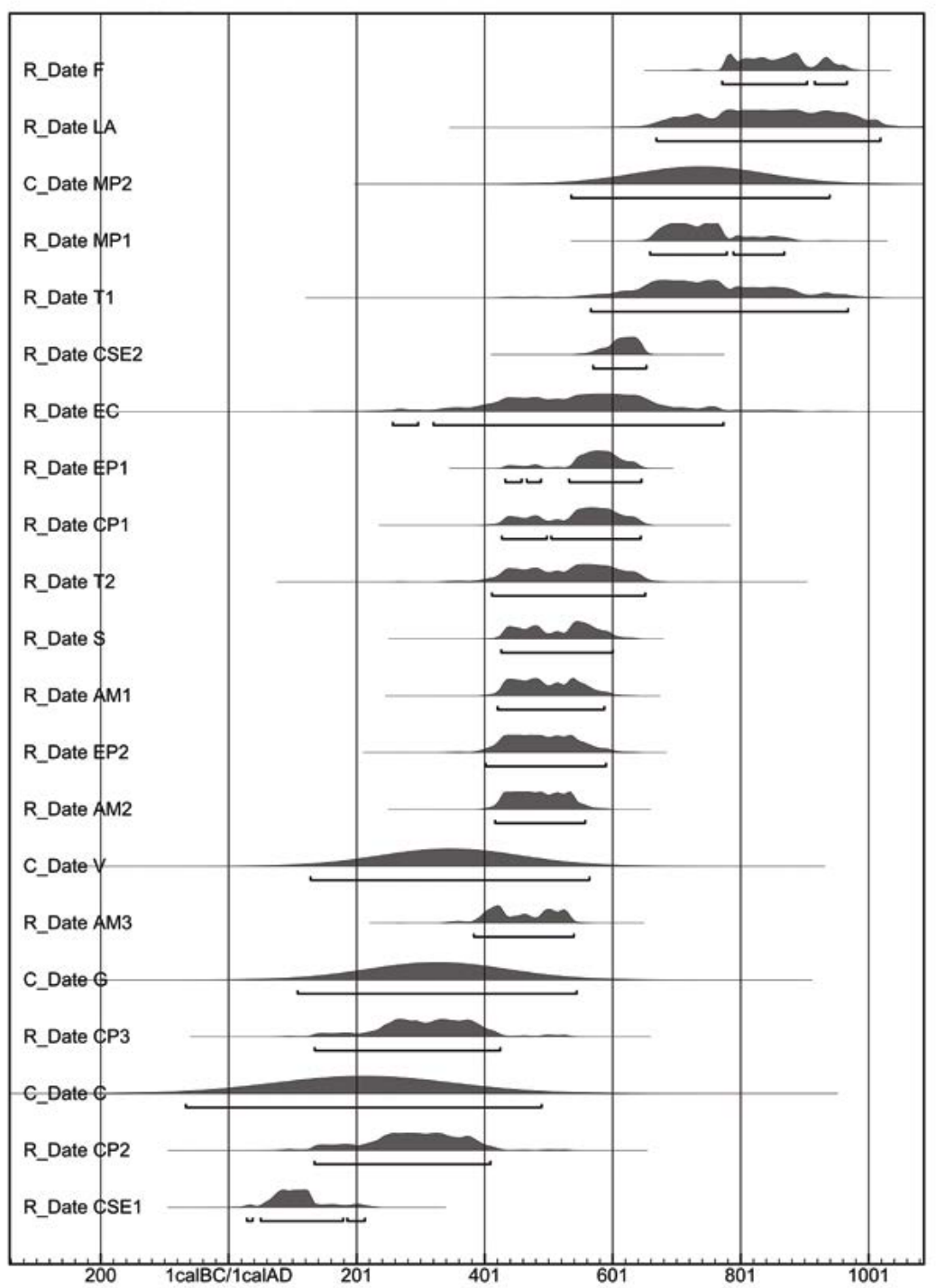

Figura 4. Dataciones absolutas en contextos de la cuenca del Duero. Dataciones absolutas en contextos de la cuenca del Duero. MP. La Mata del Palomar; EP. El Pelambre; AM. Alto del Mural/Camino de los Aguanares; CP. Cárcava de la Peladera; CSE. Cristo de San Esteban; EC. El Cuquero; S. Saelices el Chico; LA. La Armuña; G. Gallegos; F.Fuenteungrillo; T.Tedeja; C.Carratejera; V. Villafilar (elaboración propia a través de Oxcal 4.3). 


\begin{tabular}{|c|c|c|c|c|c|}
\hline CTO & $\begin{array}{l}\text { MÉTODO DE } \\
\text { PRODUCCIÓN }\end{array}$ & DEPURACIÓN & $\begin{array}{c}\text { COCCIÓN } \\
\text { MAYORITARIA }\end{array}$ & $\begin{array}{c}\text { COLOR } \\
\text { GENERAL DE } \\
\text { LAS PASTAS }\end{array}$ & TIPO DE PASTA \\
\hline PREH $^{1}$ & A mano & Baja & Mixta & Pardas o negras & - \\
\hline TS/TSHT & $\begin{array}{l}\text { Molde/rotación } \\
\text { rápida }\end{array}$ & Alta/Muy alta & Oxidante & Anaranjadas & Sedimentaria \\
\hline $\begin{array}{c}\text { CIS/ } \\
\text { TSGRIS }\end{array}$ & Rotación rápida & Alta & Mixta/reductora & Gris o negra & Sedimentaria \\
\hline CCRA & Rotación rápida & Media/alta & Oxidante & Anaranjadas & Sedimentaria \\
\hline CCRB & Rotación rápida & Baja & Oxidante & $\begin{array}{c}\text { Anaranjadas/ } \\
\text { pardas }\end{array}$ & Micácea/granítica \\
\hline PINTADA & Rotación rápida & Alta & Oxidante & $\begin{array}{l}\text { Anaranjada (con } \\
\text { pintura de color } \\
\text { ocre) }\end{array}$ & Sedimentaria \\
\hline TRA & Rotación rápida & Alta & Reductora & Gris & Sedimentaria \\
\hline TRB & Rotación rápida & Media/baja & Reductora & Gris o negra & $\begin{array}{c}\text { Sedimentaria } \\
\text { (mica plateada) }\end{array}$ \\
\hline TRB1 & $\begin{array}{l}\text { ¿Rotación } \\
\text { rápida? }\end{array}$ & Baja & Reductora & Negra & Micácea/granítica \\
\hline TRB2 & $\begin{array}{l}\text { ¿Rotación } \\
\text { rápida? }\end{array}$ & Media/baja & Oxidante/mixta & Anaranjadas & Micácea/granítica \\
\hline TRB3 & Rotación rápida & Media/baja & Mixta & Parda o gris & Sedimentaria \\
\hline TRC & Rotación rápida & Media/alta & Reductora & Gris o negra & Sedimentaria \\
\hline TRC1 & Rotación rápida & Alta & Oxidante/mixta & Naranja (exterior) & Sedimentaria \\
\hline TLA & Rotación lenta & Baja & Mixta & Parda & $\begin{array}{l}\text { Sedimentaria } \\
\text { (mica plateada) }\end{array}$ \\
\hline TLB & $\begin{array}{l}\text { Rotación lenta/ } \\
\text { mano }\end{array}$ & Baja & Reductora & Gris & Sedimentaria \\
\hline TLB1 & $\begin{array}{l}\text { Rotación lenta/ } \\
\text { mano }\end{array}$ & Baja & Mixta & $\begin{array}{l}\text { Gris, blanca, } \\
\text { rosácea }\end{array}$ & Micácea/granítica \\
\hline TLC & Rotación lenta & Media & Mixta & Parda & $\begin{array}{c}\text { Sedimentaria } \\
\text { (mica plateada) }\end{array}$ \\
\hline
\end{tabular}

Figura 5. Principales características de las CTO presentes en los conjuntos cerámicos analizados (elaboración propia). 1 Aportada en todos los casos como material residual de fases anteriores del yacimiento. Para una discusión de este proceso ver (Tejerizo García, 2017a).

calera 2015) y que implicó profundos cambios en la producción cerámica. Quizá el hecho más significativo operado en este período es la progresiva desaparición en los contextos de la terra sigillata hispánica tardía (TSHT). El estudio estratigráfico exhaustivo de algunos conjuntos del entorno de Madrid han determinado que la producción de TSHT llega a su final a mediados del siglo $\mathrm{V}$ d. n. e., posiblemente a lo largo del segundo tercio, si bien la recepción y uso de este material podría prolongarse en el tiempo (Juan Tovar 2012a; Vigil-Escalera 2013, 2015). En los yacimientos analizados en el centro y noroeste peninsular el proceso es muy similar. A lo largo de la quinta centuria se asiste a una disminución progresiva de las producciones de la TSHT desde una significativa presencia en contextos que podemos insertar dentro del primer tercio de la quinta centuria como Villafilar o Carratejera $\left(64,4 \%{ }^{9}\right.$ de fragmentos y $28,3 \%$ del peso; y 21,1 $\%$ de fragmentos y $3,4 \%$ del peso respectivamente). Estos porcentajes se mantienen en los contextos de mediados de la quinta centuria de sitios como Castro Ventosa (29\% de fragmentos y 15,2\% del peso) pero

\footnotetext{
${ }^{9}$ En el contexto de Villafilar es evidente que los métodos de selección favorecieron las cuantificaciones de TSHT sobre otras producciones.
} 


\begin{tabular}{|c|c|c|c|c|c|c|c|c|c|c|c|c|c|c|c|c|c|c|c|c|c|c|c|c|c|c|c|c|c|c|}
\hline \multirow{2}{*}{ 䍗 } & $\approx$ & \pm & s. & s. & $m^{2}$ & & & $\approx$ & & $\frac{ \pm}{d}$ & $\stackrel{ \pm}{\approx}$ & i & $\vec{b}$ & $\begin{array}{l}\infty \\
i \\
i n\end{array}$ & $\stackrel{\infty}{=}$ & \pm & $\stackrel{-1}{=}$ & $\infty$ & ले & 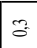 & $\therefore$ & & . & ले & $\vec{\infty}$ & + & $\vec{g}$ & $\therefore$ & ले & 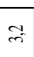 \\
\hline & 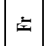 & - & qे & $\bar{i}$ & $\cong$ & . & & ส & & $\infty$ & $\tilde{2}$ & f & $n^{2}$ & $\overrightarrow{9}$ & $=$ & $\underset{i}{0}$ & $F$ & 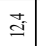 & $\begin{array}{l}\infty \\
0 \\
0\end{array}$ & $=$ & $\stackrel{\vec{s}}{=}$ & & . & $\stackrel{\infty}{\sim}$ & वे & in & $\vec{i}$ & $\stackrel{2}{g}$ & $\mathfrak{\Xi}$ & $\infty$ \\
\hline \multirow{2}{*}{ 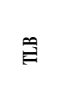 } & $\approx$ & 品 & & $\stackrel{\infty}{\infty}$ & $\approx$ & F & $\approx$ & $\begin{array}{l}0 \\
0\end{array}$ & 启 & . & $\stackrel{i}{i}$ & $\stackrel{I}{I}$ & 胥 & $\vec{\lambda}$ & $\cong$ & $\overline{8}$ & है & 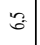 & $\bar{\nabla}$ & $\overline{\text { ते }}$ & $\infty$ & अ & $\stackrel{\square}{\approx}$ & $\sim$ & $\vec{i}$ & ' & $=2$ & $\overline{8}$ & $\stackrel{i}{i}$ & $\overline{\mathrm{i}}$ \\
\hline & $\Rightarrow$ & - & . & $=$ & $\stackrel{\infty}{\circ}$ & $\tilde{I}$ & $\cong$ & $\approx$ & $\therefore$ & . & $n^{2}$ & $F$ & \& & $m$ & $\stackrel{+}{i}$ & 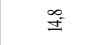 & $\bar{\Omega}$ & $\stackrel{\infty}{-}$ & $\stackrel{\Xi}{\ominus}$ & in & t. & 3 & $=$ & $\vec{q}$ & $\therefore$ & ' & \pm & $\stackrel{2}{\varrho}$ & $\stackrel{\circ}{-}$ & $\bumpeq$ \\
\hline \multirow{2}{*}{ 离 } & $=$ & ' & . & & . & & 0 & $\because$ & & $\overrightarrow{1}$ & 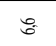 & 苦 & . & $\vec{n}$ & $\bar{F}$ & . & $\simeq$ & $\underset{\text { i }}{\text { i }}$ & $\subseteq$ & a & $\mid \begin{array}{l}\infty \\
\stackrel{\alpha}{q}\end{array}$ & & . & $\approx$ & $\infty$ & $\bar{\lambda}$ & 品 & $\underline{\underline{\alpha}}$ & $\mathbb{i}_{i}$ & $\bar{g}$ \\
\hline & $\Rightarrow$ & . & . & & . & . & $\therefore$ & $\stackrel{0}{0}$ & & 5 & 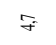 & à & . & in & $\vec{\infty}$ & . & $\because$ & $m^{2}$ & $\infty_{0}^{\infty}$ & $\begin{array}{l}\infty \\
\cong\end{array}$ & $\approx$ & & . & $\stackrel{ \pm}{=}$ & s. & $\therefore$ & 字 & 品 & $\bar{m}$ & ¿ \\
\hline \multirow{2}{*}{$\overline{\widetilde{F}}$} & $\approx$ & . & . & ' & . & . & . & & & . & ' & $\stackrel{\infty}{\infty}$ & ؟̊ & & & $\stackrel{\Xi}{-}$ & & $\Rightarrow$ & $\underset{\sim}{\infty}$ & $\bar{m}$ & $\overrightarrow{\text { ते }}$ & & . & ' & 3 & ' & $\cong$ & . & & \\
\hline & 涪 & . & . & & . & ' & . & & & . & & aี & 'ે & & & $g$ & & $\stackrel{g}{\circ}$ & $\underset{7}{q}$ & $\stackrel{\rho}{\varrho}$ & $\stackrel{\infty}{\infty}$ & & . & . & $\Rightarrow$ & . & $\because$ & . & & . \\
\hline \multirow{2}{*}{$\breve{\cong}$} & $\approx$ & $z^{2}$ & 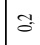 & $\because z$ & $=$ & ' & $=$ & $\vec{\Xi}$ & $\stackrel{\dot{m}}{\mathrm{~s}}$ & $=$ & Ğ & $\stackrel{\infty}{\infty}$ & $F$ & خે & 王 & $\stackrel{s}{\circ}$ & & $\stackrel{\sim}{*}$ & $\because$ & $\because$ & $\underset{d}{\pi}$ & |寺 & $\mid \begin{array}{c}0 \\
0 \\
0\end{array}$ & $\stackrel{1}{\infty}$ & $\therefore$ & $=$ & $=$ & $\because 2$ & $\stackrel{\circ}{=}$ & \\
\hline & is & - & 3 & $\Rightarrow$ & $\stackrel{\infty}{\circ}$ & . & $=$ & $\subseteq$ & $\approx$ & 5 & $\bar{\cong}$ & $\infty_{i}^{\infty}$ & $\infty$ & नें & ते & $\bar{\infty}$ & & f & $\vec{q}$ & $=$ & ${ }_{i}^{0}$ & $\bar{x}$ & 6 & $\stackrel{\circ}{\circ}$ & 8 & $a$ & $\vec{n}$ & $\because$ & 古 & . \\
\hline \multirow{2}{*}{$\overline{\widetilde{\Xi}}$} & $\approx$ & $\vec{\infty}$ & ' & $\bar{\infty}$ & . & \begin{tabular}{|c|}
$\infty$ \\
$\stackrel{0}{\circ}$ \\
$:$
\end{tabular} & $\therefore$ & $\approx$ & $\simeq$ & $\cong$ & $\stackrel{\infty}{\circ}$ & $\underline{g}$ & $\simeq$ & 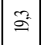 & & $\stackrel{\vec{n}}{n_{n}}$ & 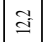 & II & $\bar{\Omega}$ & . & $\therefore$ & & $\begin{array}{l}\infty \\
\infty\end{array}$ & . & . & $\sim$ & $\therefore$ & . & +o & $\tilde{\varrho}$ \\
\hline & is & $i^{2}$ & . & $\infty$ & . & $\mid \begin{array}{l}\infty \\
\square \\
\square\end{array}$ & $\simeq$ & 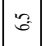 & - & $n^{2}$ & $n$ & בे & $\stackrel{\circ}{\infty}$ & 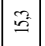 & & $\stackrel{\infty}{6}$ & $\stackrel{\circ}{\varrho}$ & $\mathcal{\lambda}$ & $\cong$ & . & $\approx$ & & 8 & . & . & $m$ & $\stackrel{\infty}{\infty}$ & . & 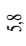 & $\simeq$ \\
\hline \multirow{2}{*}{$\cong$} & $\approx$ & $\stackrel{.}{ \pm}$ & $\bar{m}$ & 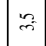 & 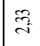 & $\ddot{m}$ & के & $\stackrel{\infty}{\mathfrak{I}}$ & 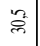 & స్লे & $\tilde{n}$ & $\begin{array}{l}0 \\
\text { fo }\end{array}$ & $\overbrace{\tilde{m}}^{\infty}$ & ठి. & 䓌 & qे & $\therefore$ & $\stackrel{\infty}{\rightleftharpoons}$ & $\infty$ & ल & 疋 & $\bar{్}$ & . & $₹$ & t. & F & đa & 조 & f & हె \\
\hline & 호 & $\approx$ & 于 & 2 & $\therefore$ & $\tilde{b}$ & $\approx$ & $\stackrel{\Xi}{=}$ & 壳 & 案 & Fे & 㐿 & 森 & $\cong$ & ఫे & $F$ & $\cong$ & 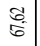 & 守 & 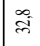 & 芯 & $\frac{\mathrm{m}}{\mathrm{m}}$ & . & हे & $\infty$ & $\bar{m}$ & $\approx$ & 导 & a & F \\
\hline \multirow{2}{*}{$\widehat{\cong}$} & $=$ & $\Rightarrow$ & ' & $\underset{i}{*}$ & . & $\approx$ & - & $\Rightarrow$ & $\Rightarrow$ & , & $\sim$ & 总 & ' & 3 & $\Rightarrow$ & $\stackrel{\circ}{\circ}$ & 2 & $\overline{0}$ & 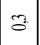 & 2 & ' & I & . & f & ' & $\subseteq$ & 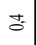 & . & & ' \\
\hline & 宝 & 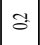 & . & $i^{2}$ & . & $\equiv$ & \pm & $\Rightarrow$ & $\vec{\sigma}$ & . & f & \pm & . & $\exists$ & + & $\therefore$ & $\therefore$ & 壱 & - & $=$ & . & 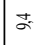 & . & $\underset{\infty}{+\infty}$ & . & $=$ & 3 & . & & ' \\
\hline \multirow{2}{*}{ 言 } & $\approx$ & ส্ণ & $\stackrel{2}{n}$ & 寺 & $\bar{q}$ & & . & $\sim$ & & . & & . & . & & & . & 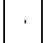 & $\cdot$ & . & ' & ' & ' & . & . & ' & . & . & . & & ' \\
\hline & 히 & $\stackrel{\infty}{+}$ & $\stackrel{\infty}{\Theta}$ & 5 & 赵 & & . & 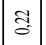 & 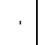 & . & ' & . & & & & . & 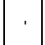 &. & . & . & . & & . & . & . & . & . & . & & . \\
\hline \multirow{2}{*}{ 莽 } & $=$ & $\vec{\sim}$ & वั. & i & ż & $\approx$ & - & $\because$ & ले & 告 & ב' & . & . & $\therefore$ & I & . & $a$ & $\underset{\sim}{\infty}$ & $\stackrel{\infty}{=}$ & ' & $\stackrel{m}{m}$ & & $\stackrel{\infty}{=}$ & $\Rightarrow$ & 27 & $\therefore$ & . & ' & & . \\
\hline & 它 & $\approx$ & F & o & चే & $\tilde{\sigma}$ & - & g & స్ల & 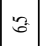 & F & . & . & $\stackrel{0}{\circ}$ & $\therefore$ & . & $\approx$ & $\Xi$ & $\stackrel{-}{\circ}$ & . & $\Rightarrow$ & & $=$ & $\Rightarrow$ & $\therefore$ & - & . & . & & . \\
\hline \multirow{2}{*}{ 丞 } & $\approx$ & $\vec{i}$ & . & $\begin{array}{l}\infty \\
\sim \\
\sim\end{array}$ & - & . & . & : & $\stackrel{0}{\circ}$ & . & & . & . & & 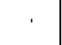 & . & . & $\cdot$ & $\bar{\sigma}$ & . & . & . & \&. & . & . & ' & . & . & & . \\
\hline & i & $\stackrel{\infty}{m}$ & . & $\cong$ & $\stackrel{t}{=}$ & . & . & \begin{tabular}{|l}
$\infty$ \\
$\infty$
\end{tabular} & $\stackrel{\infty}{\infty}$ & . & ' & . & & & & . & . & $\cdot$ & 3 & . & . & 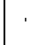 & $m$ & . & . & . & . & . & . & \\
\hline \multirow{2}{*}{ 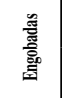 } & 2 & . & . & ' & . & . & . & $\cong$ & కิ & . & & . & . & & ' & . & . & . & . & . & . & . & . & . & ' & . & . & . & & ' \\
\hline & $z$ & . & . & . & . & . & . & $\Phi$ & $\approx$ & . & . & . & . & & & . & . & . & . & . & . & . & . & . & . & . & . & . & 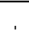 & . \\
\hline \multirow{2}{*}{ s } & $\approx$ & $\therefore$ & . & . & . & . & . & $\because$ & 3 & $\vec{\sigma}$ & ' & . & & & ' & . & . & . & . & ' & . & . & ' & . & . & ' & ' & . & ' & . \\
\hline & $\Rightarrow$ & $\therefore$ & . & . & . & . & . & $\because$ & 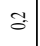 & $\stackrel{2}{=}$ & & . & . & & & . & 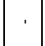 & . & . & . & . & 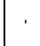 & . & . & . & . & . & . & & . \\
\hline \multirow{2}{*}{ 总 } & $\approx$ & $\Rightarrow$ & g & 志 & 壳 & . & . & It & . & . & ' & . & . & & & . & . & . & . & . & '. & , & . & . & . & . & . & . & . & . \\
\hline & $\Rightarrow$ & 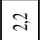 & $\because z$ & व & t & . & . & \pm & ' & . & . & . & . & & . & . & . &. & . & . & . & 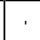 & . & . & . & . & . & . & . & . \\
\hline \multirow{2}{*}{ 最畐 } & $\approx$ & ते & $m^{2}$ & $\infty$ & 궁 & $\therefore$ & - & 王 & $\stackrel{\circ}{\rightarrow}$ & $\vec{\imath}$ & $n^{2}$ & . & . & 孛 & ㄹㅇㅇ & . & śt & $a^{2}$ & . & . & . & ' & . & $\frac{m}{0}$ & . & a & . & . & & . \\
\hline & 혼 & $\overrightarrow{8}$ & $\stackrel{\infty}{\Omega}$ & $\infty$ & 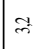 & in & + & $\Xi$ & $\stackrel{8}{\circ}$ & $\Rightarrow$ & $\stackrel{m}{m}$ & . & . & $m$ & \&̊ & . & $\vec{\tau}$ & 象 & . & . & . & & . & to & . & $\cong$ & . & . & & . \\
\hline F & $\approx$ & 3 & $\overrightarrow{0}$ & $D_{0}^{\infty}$ & . & . & . & $\therefore$ & & . & & $\tilde{s}$ & . & & . & . & . & $\cdot$ & 8 & 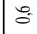 & . & . & . & . & $=$ & . & . & . & & . \\
\hline & i & $\because$ & $\Rightarrow$ & ते & . & . & . & तี & & . & . & 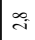 & . & & & . & . &. & - & $\stackrel{f}{m}$ & . & . & . & . & $\because$ & . & . & . & . & . \\
\hline$\widehat{\vec{z}}$ & $\approx$ & $\cdot$ & z & & 그 & . & . & 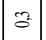 & & . & & . & . & & & . & . & $\cdot$ & $\bar{s}$ & . & . & . & . & . & . & - & . & . & & . \\
\hline 音 & 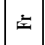 & $\cdot$ & तิ & & $\stackrel{\circ}{\cong}$ & . & . & $\therefore$ & & . & . & . & & & & . & . & $\cdot$ & $m_{3}$ & . & ' & & . & . & . & m & . & . & ' & . \\
\hline & $=$ & - & छे & & . & . & . & $\%$ & & . & f & . & $\cong$ & 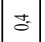 & $\cong$ & . & $\cong$ & . & $\bar{n}$ & శ్లi & $\vec{i}$ & & . & d & $\stackrel{a}{a}$ & . & $\stackrel{i}{i}$ & . & & \\
\hline & 호 & - & 로 & & . & . & . & $\frac{\infty}{0}$ & & , & $n^{2}$ & . & $\Rightarrow$ & $\simeq$ & $\stackrel{\infty}{=}$ & . & $\begin{array}{l}\infty \\
\text { జñ }\end{array}$ & . & $\overline{6}$ & $\vec{a}$ & $\infty$ & & . & $\stackrel{2}{\Leftrightarrow}$ & $\overrightarrow{\underline{\alpha}}$ & . & ले & & & \\
\hline 突离 & & 응 & $\stackrel{\approx g}{g}$ & $\therefore$ & సి & $\bar{\infty}$ & 拿 & สิ & $\vec{\sigma}$ & 学 & 䟥 & $\stackrel{\varrho}{\cong}$ & $\stackrel{\infty}{\dddot{q}}$ & $\cong$ & sి & त्र & $\bar{i}$ & 品 & ஓ & $\infty$ & $\propto$ & $\infty$ & $\approx$ & ః્તે & 鿖 & $\propto$ & $\stackrel{\circ}{g}$ & g̃ & $\approx$ & $\approx$ \\
\hline 畜 & & 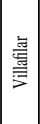 & 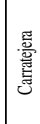 & 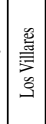 & 总 & 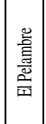 & $\mid$ & 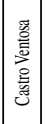 & 总 & 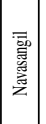 & 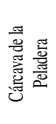 & 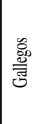 & 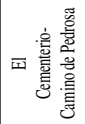 & 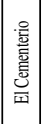 & 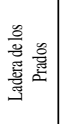 & 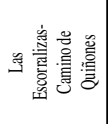 & 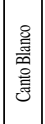 & 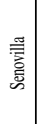 & 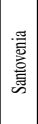 & 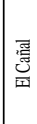 & & 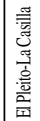 & 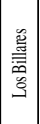 & 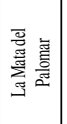 & 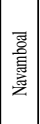 & 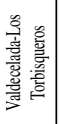 & 을 & 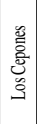 & & 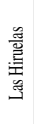 \\
\hline
\end{tabular}


caen en aquellos contextos posteriores, que suponen las últimas producciones que llegan a los yacimientos (Navasangil $=9,01 \%$ de fragmentos y 2,1 \% del peso y Viladonga $=5,06 \%$ de fragmentos y $1,56 \%$ del peso). Para el último cuarto del siglo $\mathrm{V}$ d. n. e. la TSHT aparece como residual en los contextos de Cárcava de la Peladera, El Pelambre o Gallegos (en torno a un 3 $\%$ de fragmentos y entre 0,5 y $2 \%$ del peso), ya a caballo entre la quinta y la sexta centuria, a tenor de las dataciones realizadas en los dos primeros yacimientos. Cabe destacar que algunas decoraciones de estos últimos momentos de la TSHT, como es la decoración estampillada, que aparece en yacimientos como Castro Ventosa, Viladonga o Carratejera, puede datarse de forma bastante aproximada en la primera mitad del siglo V (Vigil-Escalera 2015: 299-300).

Un proceso similar operaría sobre otro tipo de producciones provenientes del mundo romano tardoimperial, como son las cerámicas pintadas denominadas "de tradición indígena" (Abascal Palazón 1986; Bustamante Álvarez 2016). Al igual que la TSHT, aparecen en su fase final dentro de los repertorios de ajuar de las necrópolis postimperiales. Así, en contextos como Carratejera (menos del 2,7 \% de fragmentos y $0,2 \%$ del peso), El Judío (17,6 \% de fragmentos y 5,2 $\%$ del peso $)^{10}$ o el yacimiento de Las Lagunillas $(4,5$ $\%$ de fragmentos) (Centeno Cea et alii 2010) aparece ya de forma casi testimonial, desapareciendo hacia finales de la quinta centuria y estando ausente en el resto de contextos analizados, salvo una presencia mínima en contextos de asentamientos fortificados como Castro Ventosa $(0,5 \%$ de fragmentos y $0,3 \%$ del peso) o en algunas aldeas del s. VI d. n. e. como Santovenia (0,3\% de fragmentos y $0,1 \%$ del peso).

La progresiva disminución en la producción y distribución de la TSHT y la redefinición de las escalas productivas fueron determinantes para la, también progresiva, aparición de otro tipo de productos que vendrían, en primera instancia, a competir con ella y, en el largo recorrido, a sustituirlas. Entre estas cabe destacar dos en el contexto del centro peninsular: la terra sigillata gris y las cerámicas imitación de sigillata (CIS) ${ }^{11}$.

Lo que aquí llamaremos terra sigillata gris ha recibido diversas denominaciones a lo largo del tiempo, que no siempre han hecho referencia al mismo tipo de producción. Se trata de una producción cuyas

${ }^{10}$ Su sobrerrepresentación en cuanto al número de fragmentos viene dada por la aparición de un cacharro prácticamente entero pero muy fragmentado.

$11 \mathrm{Si}$ bien hay que mencionar la presencia de terra sigillata hispánica meridional (TSHTM) en el contexto de Navasangil, como el yacimiento más septentrional en el que se ha localizado hasta el momento (Tejerizo García 2017b). características definitorias serían la presencia efectiva de un barniz o engobe de color negro o grisáceo y no únicamente bruñido, que lo separaría de otro tipo de producciones con una cadena tecnológica distinta (por ejemplo, las que hemos denominado aquí como TRA o TRB), y la presencia de motivos estampillados o burilados como elemento decorativo característico. Así, sus similitudes con la llamada "derivada de la sigillata paleocristiana" (DSP) del sur de la Galia llevó a denominarla como "Sigillatas Paleocristianas", de las que se diferenciaron las "grises" de las "anaranjadas" término que tuvo cierto grado de aceptación (Caballero Zoreda 1972; Caballero Zoreda y Argente Oliver 1975; Nozal Calvo y Puertas Gutiérrez 1996). Por su parte, L.C. Juan la ha introducido dentro de las Cerámicas Imitación de Sigillata (CIS) (Juan Tovar 2012a, 2012b) si bien su cadena tecnológica, aparición en los contextos y redes de distribución son perfectamente distinguibles de otras producciones clasificadas como CIS y considero deben de analizarse separadamente.

La aparición de la terra sigillata gris (TSGris) en los contextos cerámicos se produciría en torno al primer tercio de la quinta centuria, como ya se ha apuntado en otros trabajos (Centeno Cea et alii 2010). Como vimos, aparece ya, aunque en cantidades muy minoritarias, en los últimos momentos de ocupación de las villas tardoimperiales. El caso de la villa de $\mathrm{La}$ Olmeda es especialmente significativo, ya que se localizó un conjunto de 172 fragmentos de este tipo cerámico que fue objeto de un trabajo monográfico (Nozal Calvo y Puertas Gutiérrez 1996), correspondiendo a un porcentaje mínimo del conjunto cerámico total. Similares porcentajes se documentan en contextos aldeanos del primer tercio o mediados de la quinta centuria como Villafilar, Carratejera o El Judío, donde no superan el $2 \%$ del conjunto total. En este sentido, el contexto de Castro Ventosa funciona de manera similar, dado que presenta altos porcentajes de sigillata tardía y un bajo porcentaje de TSGris $(0,4$ $\%$ de fragmentos y $0,04 \%$ del peso), sugiriendo cronologías similares.

A medida que avanza la quinta centuria la presencia de este tipo cerámico se intensifica. Así, en contextos de mediados de la quinta centuria o del tercer cuarto del siglo V, como en Las Lagunillas -donde fue denominado como GRIST1-, su porcentaje llega hasta el $20 \%$. Estas producciones también están presentes de una forma significativa en los asentamientos fortificados, como muestran los conjuntos de Cancho del Confesionario (Caballero Zoreda y Megías Pérez 1977) o El Castillón, donde presenta una decoración burilada característica (Sastre Blanco et alii 2018); o en antiguas ciudades romanas de Astorga (Paz Peral- 
ta 2013) $)^{12}$ o Ávila (Estremera et alii 2006). El final de esta producción debe producirse a finales de la quinta centuria, momento en el que ya aparecen de forma muy escasa, como en la primera fase de Congosto (Vigil-Escalera y Strato 2013: 255-256), o desaparecidas del todo, como ocurre en Cárcava de la Peladera o El Pelambre.

Dos contextos son especialmente significativos en cuanto a la producción de terra sigillata gris: Villanueva de Azoague y Astorga; que, de hecho, han sido propuestos como zonas de producción de esta cerámica (López Rodríguez y Regueras Grande 1987; Paz Peralta 2013). El sitio de Los Villares (Villanueva de Azoague, Zamora) es muy interesante en este sentido, pues mostraría un momento de transición en las producciones de mediados de la quinta centuria. Una de las producciones más relevantes localizadas en este sitio fue la de una TSHT con significativos restos de quemados que dejan una superficie negra en partes de la cerámica, si bien conserva parte de su barnizado rojo y anaranjado original. Este lote fue localizado en una "bolsada" que podría corresponder a algún tipo de basurero asociado a un posible punto de producción de esta cerámica.

La otra producción sustitutiva de la TSHT es la que L. C. Juan Tovar ha denominado como cerámica imitación de sigillata o CIS (Juan Tovar 2012a, 2012b). Sus características esenciales serían muy similares a lo descrito para la terra sigillata gris, si bien se diferencia por la ausencia de barniz sinterizado, las superficies muy alisadas y el tipo de cocciones recibidas, más irregulares y que dejarían superficies indistintamente oxidantes o reductoras, que han sido denominadas como "avellanas" en algunas publicaciones. Al igual que la TSGris, una de sus características definitorias sería la decoración estampillada, que no está presente en todas las cerámicas, pero sí será el elemento decorativo principal en esta producción. La cronología de las CIS, a partir del análisis de estas producciones en algunos yacimientos con secuencias estratigráficas fiables, lleva a enmarcarlas en una cronología "centrada en la segunda mitad del siglo V" y no sobrepasar en exceso la sexta centuria (Juan Tovar 2012b: 123; Tejerizo García 2018). Efectivamente, su aparición, normalmente muy minoritaria en los conjuntos, se asocia a los yacimientos datados en esa horquilla, como son Villafilar, El Judío, Viladonga, Castro Ventosa o, muy significativamente Navasangil, donde llegan a representar un $11,3 \%$ de los fragmentos y un $9,1 \%$ del peso.

Es en estos momentos, en torno a finales de la quinta centuria e inicios de la sexta, cuando se produce la

${ }^{12} \mathrm{Si}$ bien este autor data estas producciones entre finales del siglo IV e inicios del siglo VI. introducción definitiva de producciones depuradas que ya han perdido características definitorias como sería la presencia de cualquier tipo de engobe o barniz y su sustitución por los bruñidos. Esta sería la característica esencial de lo que se ha denominado aquí como TRA, cadena que equivaldría grosso modo a lo que L.C. Juan Tovar definió como CIS "no tratadas", caracterizadas por la ausencia de tratamiento exterior pero que todavía presentaría, en ocasiones, decoración estampillada (Juan Tovar 2012b: 98). Así mismo, estas producciones depuradas y bruñidas son las que comúnmente se han denominado, pensamos incorrectamente, como "cerámicas visigodas" (una discusión sobre este tipo de categorías en Tejerizo García 2015), si bien este término ha acabado por definir, en ocasiones, a todo el mundo de las cerámicas reductoras altomedievales. Una de sus principales características definitorias en las primeras producciones de este tipo cerámico, la decoración estampillada, acaba por desaparecer del registro en favor de las decoraciones incisas y bruñidas (Tejerizo García 2018). Por el contrario, el resto de elementos de la cadena tecnológica será conservado posteriormente, cuya aparición significativa en los conjuntos se inicia a finales de la quinta centuria y que será una de las características de los conjuntos de la sexta y séptima centuria, como se verá en el siguiente apartado.

La transformación en la producción cerámica también es claramente visible en los ciclos de la denominada como "cerámica común", caracterizada principalmente por una cocción oxidante o mixta irregular. Esta cerámica desaparecerá progresivamente en este período, tanto en sus formas más depuradas (de "cocina", denominada aquí CCRA) como en las menos depuradas ("de almacenamiento", CCRB). Al igual que ocurre con las producciones depuradas, estas serán sustituidas a lo largo de la sexta y séptima centurias por cerámicas con características similares, pero de cocciones reductoras (denominadas aquí como TRB). Es interesante destacar que las variantes con cocción oxidante poco depuradas parecen mantenerse más en el tiempo que las producciones depuradas. Así, en contextos de la quinta centuria, las producciones CCRB se presentan en porcentajes cercanos al $30 \%$ en sitios como Carratejera, El Judío o Viladonga y se reducen drásticamente, sin desaparecer, en los contextos de la sexta centuria, con porcentajes que rondan los 2-5\%. Por su parte, la variante depurada CCRA parece desaparecer ya en la sexta centuria, manteniéndose hasta entonces en porcentajes entre el 10-18\% en sitios como Los Villares, El Judío o Castro Ventosa.

Un último aspecto que cabe destacar es que en cronologías similares en torno a mediados de la quinta centuria se interrumpe la llegada de importaciones 
extrapeninsulares. Si bien nunca son cuantitativamente significativas, se han localizado ánforas y/o producciones de sigillata africana en yacimientos como Castro Ventosa, Viladonga o Carratejera. Sin embargo, en ninguno de los yacimientos datados a partir de la sexta centuria se han documentado este tipo de materiales. Todo parece indicar que el comercio de este tipo de bienes en el interior peninsular tiene una importancia cada vez menor. Dado que la oferta no se detiene, pues se detecta en momentos posteriores en otros contextos, algunos muy cercanos (Aquilué Abadías 2003; León Asensio y Barona Barona 2013) y con especial incidencia en la costa atlántica y cantábrica (Fernández Fernández 2014), la razón fundamental sería una contracción de la demanda y de la capacidad de adquisición de estos productos por las sociedades rurales del centro y noroeste peninsular, así como una creciente dificultad para su comercialización hacia los territorios del interior peninsular desde los lugares de recepción. Esto es, un desmantelamiento de los sistemas previos de distribución y de los mecanismos de redistribución.

\subsection{LAS PRODUCCIONES CERÁMICAS DE MEDIADOS DEL SIGLO VI- MEDIADOS DEL SIGLO VIII EN LA CUENCA DEL DUERO}

En términos de producción cerámica, a partir de mediados de la sexta centuria y hasta prácticamente mediados de la octava, las transformaciones tecnológicas documentadas son mucho más sutiles y menos drásticas y, en cualquier caso, mucho menos significativas que las observadas en el período anterior. Esto ha sido uno de los determinantes para la paralización de los estudios cerámicos de este período. En otras palabras, la desaparición de "fósiles directores" a partir de mediados de la sexta centuria en adelante dificultó de forma sustancial el análisis de la cerámica, dado que no existían claros apoyos tecnológicos y cronológicos que permitan datar con precisión los contextos cerámicos analizados. Sin embargo, mediante la metodología propuesta basada en el análisis exhaustivo y en conjunto de toda la cerámica de una amplia variedad de yacimientos datados en este período sí que permite vislumbrar transformaciones a lo largo del tiempo que permiten hacer una propuesta de secuenciación. En este sentido, cuatro son los cambios principales detectados en el repertorio cerámico.

Quizá la transformación más relevante detectada a partir de la sexta centuria es la introducción progresiva de producciones realizadas a través de sistemas de rotaciones más discontinuas, que dejan superficies y líneas de torneado más irregulares. Este es un hecho ya ampliamente reconocido en los contextos madrileños (Vigil-Escalera 2003, 2006, 2007a) y que también ha sido detectado en la cuenca del Duero (Centeno Cea y Villanueva Zubizarreta 2018; Larrén et alii 2003; Tejerizo García 2016a). En estos trabajos se muestra como este tipo de producciones comienza a ser muy significativa a lo largo de la sexta centuria, convirtiéndose en mayoritaria ya a finales de esa centuria y perdurando en el tiempo hasta la aparición de las primeras vajillas de tipo emiral temprana, datadas entre el segundo tercio del s. VIII y el primer tercio del s. IX d. n. e. (Serrano Herrero et alii 2016) e incluso posteriormente en la meseta norte (Bohigas Roldán et alii 1989). Así, la aparición de este tipo de cadenas tecnológicas (caracterizadas aquí como TLA, TLB, TLB1 y TLC) se produce desde inicios o mediados de la sexta centuria, atestiguada en conjuntos como La Cárcava de la Peladera $(4,7 \%$ del total de fragmentos y $6,6 \%$ del peso) o Gallegos (7 \% de fragmentos y 5,4 $\%$ del peso). Igualmente, se detecta una creciente importancia de este tipo de producciones en los últimos momentos de la horquilla manejada, seguramente entre mediados de la séptima centuria y mediados del siglo VIII, en contextos como la primera fase de Canto Blanco (19,5\% de fragmentos y $16 \%$ del peso), Los Cepones (30,6\% de fragmentos y $18,3 \%$ del peso) o El Ventorro (40,6\% de fragmentos y 50,8 \% del peso). Es interesante destacar que estos dos últimos contextos, sobre todo El Ventorro, no han sido objeto de una selección de material tan fuerte como otros contextos (por ejemplo, La Mata del Palomar, donde aun así esta CTO se presenta en un $11,4 \%$ de fragmentos y $9,6 \%$ del peso), lo que reforzaría la idea de las similitudes con respecto a las conclusiones cuantitativas extraídas para el área de Madrid. Con todo, se muestran ligeras diferencias con respecto a la presencia relativa de estos materiales en ambos espacios. Es muy probable que estas diferencias sean debidas, fundamentalmente, a los procesos de selección cerámica comentados anteriormente, sumado a la dificultad de detectar este tipo de diferencias a nivel macroscópico (Fig. 7).

En cualquier caso, no cabe duda de la presencia e importancia de estas producciones realizadas con tecnologías asociadas a rotaciones discontinuas en los distintos contextos. Esto ha de relacionarse con cambios sustanciales introducidos en la cadena operativa $\mathrm{y}$, fundamentalmente, con el cambio de escala de los centros de producción. Como se sugería anteriormente, en la fase anterior los centros de producción conocidos se asociaban mayoritariamente a espacios de control territorial, como es el caso de Astorga o del Cerro de la Virgen del Tormejón (Gozalo Viejo et alii 2013). A partir de mediados de la sexta centuria, estos centros parecen localizarse en los propios asentamien- 


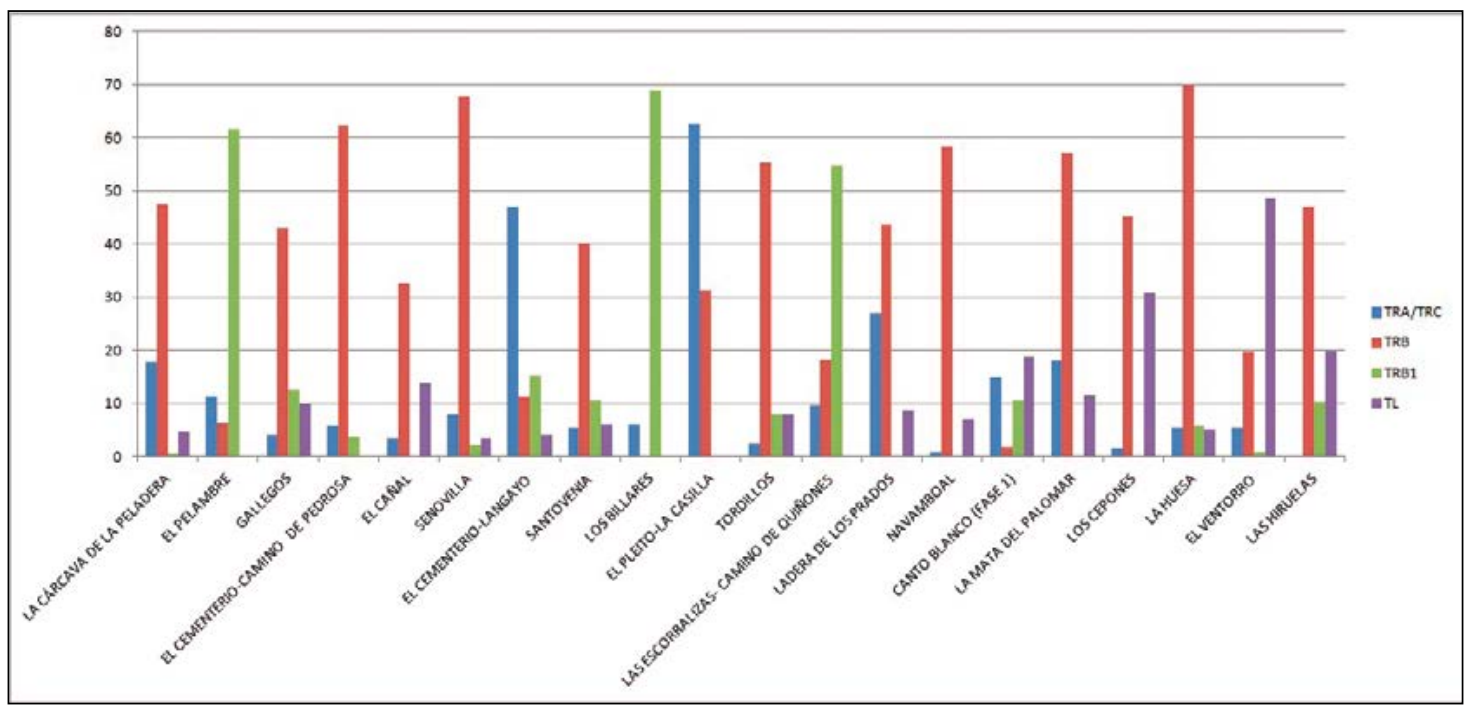

Figura 7. Comparación del número de fragmentos de las principales CTO por yacimiento (elaboración propia).

tos rurales, donde se ha documentado un amplio número de hornos (Juan Tovar et alii 2013). De esta manera, lo que se puede sugerir es que la producción cerámica sufre un cambio de escala, hacia la mayor regionalización e incluso hacia la producción en la escala local de ciertas producciones (Tejerizo García 2016a; Vigil-Escalera 2006; Vigil-Escalera y Quirós Castillo 2013). Esta idea se ve reforzada por los -aún escasos-análisis arqueométricos que se han realizado sobre esta cerámica, que mostrarían un aprovisionamiento fundamentalmente local para su producción (Centeno Cea y Villanueva Zubizarreta 2018).

El segundo elemento característico de las producciones cerámicas a partir de inicios del siglo VI d. n. e. es la imposición hegemónica de las cocciones reductoras. Este proceso se produce, como ya comentamos, de forma paulatina desde la primera mitad de la quinta centuria. Así, la cadena definida como TRB, caracterizada por la producción mediante rotaciones rápidas, cocción reductora, depuraciones medias y pastas sedimentarias aparece, en contextos datados en este momento, en porcentajes en torno al 5-9\% de fragmentos y un $3 \%$ del peso. Para inicios del siglo VI d. n. e. llegan a representar hasta la mitad del conjunto (especialmente significativos, por ejemplo, en Cárcava de la Peladera, con un 47,9\% de fragmentos y un $57,2 \%$ de peso o El Cementerio-Camino de Pedrosa, con un $44,9 \%$ de los fragmentos y un $33,8 \%$ del peso). Para la sexta y séptima centurias, supone más de un tercio de los conjuntos, llegando incluso al 60-70 \% en conjuntos como Senovilla, La Mata del Palomar, La Huesa, Navamboal o El CementerioCamino de Pedrosa. Bajo esta CTO se producen prác- ticamente todas las formas cerámicas del repertorio, aunque con especial preferencia por las formas cerradas de cocina (ollas, fundamentalmente). Esta hegemonía de las cocciones reductoras en el período comprendido entre el siglo VI y el VIII d. n. e. -y, dependiendo de la región, incluso más allá- ha sido igualmente detectado en todo el centro, norte y noroeste peninsular (Fernández Fernández y Bartolomé Abraira 2016; Vigil-Escalera 2006). Este profundo cambio tecnológico se relacionaría principalmente con diferencias en los propios procesos técnicos como el proceso de horneado-.

Un tercer aspecto significativo en términos tecnológicos es el cambio en las cerámicas de mesa y de lujo a partir de la sexta centuria. Una vez desaparecen las producciones y cadenas tecnológicas derivadas de las sigillatas, este tipo de cerámicas van a verse sustituidas por cadenas tecnológicas basadas en la cocción reductora. Estas se caracterizan por la aplicación más o menos generalizada del bruñido como elemento diferenciador de la CTO. Este bruñido tiene una doble función tanto de impermeabilización del cacharro como de decoración y marca de estatus de la propia cerámica. Se trata de una cerámica de alta calidad, con un alto grado de depuración de las pastas y delgadez de las paredes. De nuevo, este fenómeno ya había sido sugerido para estas cerámicas, si bien con diferencias en cuanto a su datación (Larrén et alii 2003). Se trataría de las cadenas operativas denominadas aquí como TRA y TRC, que ya habían sido detectadas en contextos de momentos anteriores (por ejemplo, en Villafilar o Villanueva de Azoague) pero que adquieren una importancia muy significativa a partir de la 
sexta centuria. Su porcentaje no es excesivamente alto en ninguno de los contextos, salvo excepciones como El Cementerio-Langayo o El Pleito-La Casilla, debido al reducido conjunto inventariado y a los procesos de selección cerámica que tendieron a potenciar estas producciones. Por lo general, no llegan a sobrepasar el 10-20\% del conjunto total. Esta cadena operativa está presente, sobre todo, en aquellas formas destinadas a la representación y la visibilización, como son los cuencos o los contenedores de líquidos, si bien no es raro encontrársela en una amplia variedad de formas. Al igual que el resto de las cadenas tecnológicas basadas en la producción mediante rotaciones rápidas, estas cadenas desaparecen progresivamente a medida que se avanza en la séptima y octava centuria. En los contextos tardíos como Los Cepones, La Huesa, El Ventorro o Las Hiruelas, estas producciones no superan el $5 \%$.

El último cambio significativo detectado concierne a los aparatos decorativos y a las formas de impermeabilización de las cerámicas. Si bien luego retomaremos este tema para analizar las diferencias regionales, existen algunas tendencias generales detectadas a partir de la sexta centuria. Las decoraciones estampilladas, muy características del período anterior y asociadas mayoritariamente a las cerámicas de imitación de sigillata, se rarifican enormemente en los contextos a partir del segundo cuarto del siglo VI d. n. e. (Juan Tovar 2012b; Tejerizo García 2018). En general, se puede afirmar que las decoraciones cerámicas a partir de este momento se van simplificando progresivamente tanto en la complejidad de los motivos como en su variedad. Básicamente y de forma resumida, se documentan tres formas principales de decoración, ya presentes desde la quinta centuria en el repertorio cerámico. Estas serían el bruñido (utilizado no como técnica de impermeabilización sino con fines decorativos), la incisión y, reservada a los grandes contenedores, la digitación. La variedad en la que estas decoraciones, o sus combinaciones, se presentan, es muy grande. Así, en su forma más básica, el bruñido puede aparecer formando líneas verticales u oblicuas, mientras que la incisión se presenta mediante líneas horizontales y ondas, a veces realizadas con un pequeño peine. Sin embargo, este tipo de decoraciones adquiere en ocasiones formas muy desarrolladas y complejas, con decoraciones combinadas mediante retículas de bruñidos e incisiones horizontales o en ondas; o mediante varias series de ondas a peine que se intersectan.

Sin embargo, a partir de la séptima centuria se produce una muy significativa reducción de las decoraciones, que se vuelven además muy irregulares en su trazado. Este fenómeno está en estrecha relación con el cambio tecnológico de la implantación progresiva de los sistemas de rotación discontinua para la producción cerámica. Así, las decoraciones incisas o mediante líneas de bruñidos, por su regularidad, se benefician de las rotaciones rápidas, que dejaban además las dos manos del artesano o artesana libres para poder decorar con regularidad. Mediante las rotaciones lentas, al tener que utilizar ambas manos y disponer de rotaciones menos continuadas, este tipo de decoraciones se fueron haciendo cada vez más costosas y se fueron reduciendo progresivamente. Así, en yacimientos tardíos como la segunda fase de La Mata Del Palomar, La Huesa, Los Cepones o El Ventorro se muestra una reducción, más que significativa, de las decoraciones. En otros contextos tardíos, como la última fase de Gózquez, por ejemplo (Vigil-Escalera 2007a), si bien no desaparecen, las decoraciones se rarifican en extremo.

\section{ASPECTOS FORMALES}

Abordaremos ahora algunos de los principales aspectos formales del repertorio cerámico entre los siglos V y VIII d. n. e. Por razones de espacio, únicamente se incidirá en las cuestiones más relevantes, dejando para otros trabajos análisis más pormenorizados. Para ello, seguiremos en gran medida la clasificación tipológica propuesta en el trabajo de síntesis de 2003 (Larrén et alii 2003), así como muchas de las consideraciones allí hechas que, con ligeras matizaciones, resultaron ser extremadamente acertadas.

Las formas abiertas tipo cuenco son una de las producciones más significativas del período entre el siglo V y el siglo VIII d. n. e. (Larrén et alii 2003; Vigil-Escalera 2006) (Fig. 8). Si bien a mediados de la quinta centuria se constata la desaparición en contextos de uso de formas típicas como la Ritterling 8 o la 37 tardía, estas se verán sustituidas por formas similares bajo las tecnologías denominadas "de imitación". Así, en contextos de finales de la quinta centuria hasta mediados de la sexta centuria se localizan producciones de formas muy similares a la Rigoir $3 \mathrm{a}, 6 \mathrm{~b}$, $14,15 \mathrm{a}, 18 \mathrm{o}$ variedades similares a la forma 22 . Una producción también presente es el cuenco con vertedero, documentado, por ejemplo, en el yacimiento de Navasangil. A partir de la sexta centuria muchas de estas producciones comienzan a desaparecer de los contextos, como por ejemplo las formas invasadas y las carenadas con el cuello recto, característico de algunas cerámicas de El Castillón o Castro Ventosa. Es en este momento cuando se hacen hegemónicos los cuencos carenados y los hemisféricos sin carena. La variedad de formas de los cuencos es amplia, si bien 


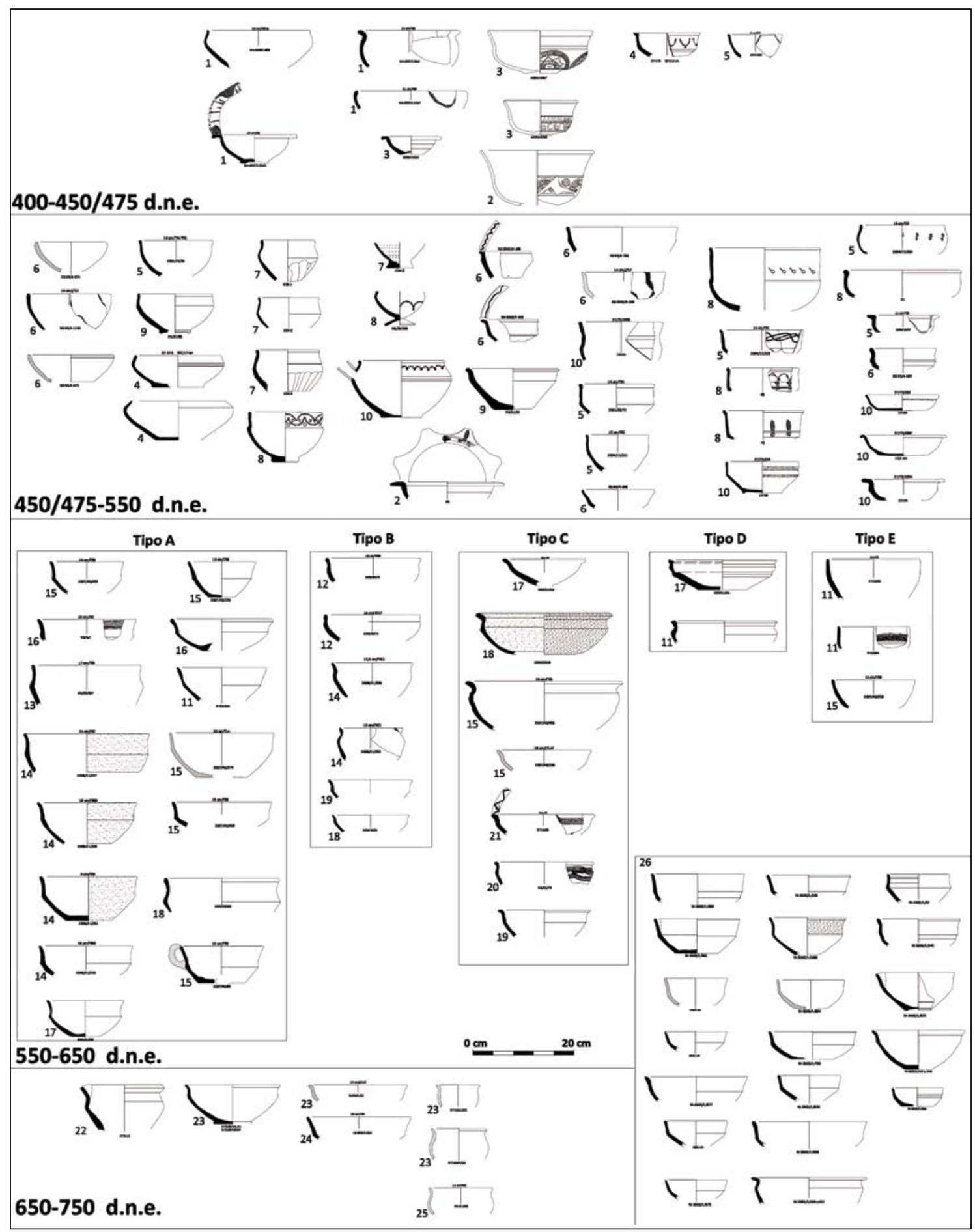

Figura 8. Propuesta de secuencia para las formas tipo cuenco. 1. Carratejera; 2. Villanueva de Azoague; 3. Villafilar; 4. Viladonga; 5. Castro Ventosa; 6. Cárcava de la Peladera; 7. El Pelambre; 8. El Castillón; 9. El Cementerio/Camino de Pedrosa; 10.Navasangil; 11. El Cementerio (Langayo); 12. El Cañal; 13. Tordillos; 14. Santovenia; 15.Senovilla; 16. Rubí de Bracamonte; 17. Ladera de los Prados; 18.Navamboal; 19. Vega de Duero; 20.Escorralizas; 21.Valdecelada/Los Torbisqueros; 22. Las Hiruelas; 23. La Huesa; 24. Los Cepones; 25. El Ventorro; 26. La Mata del Palomar (elaboración propia). 
se han podido distinguir hasta cinco tipos recurrentes a partir de mediados de la sexta centuria:

- Tipo A: cuencos carenados con la carena a media altura y labio ligeramente exvasado y redondeado. El carenado puede ser más o menos pronunciado, siendo algunos muy sutiles. Algunas de estas formas presentan un asa y pico vertedor, forma también reconocida en contextos madrileños (Vigil-Escalera 2007a).

- Tipo B: cuencos con carena especialmente alta, con labios rectos o ligeramente exvasados y redondeados.

- Tipo C: cuencos carenados caracterizados por la presencia de labio exvasado y vuelto, normalmente engrosado. Algunos bordes de estas formas se decoran, aspecto que se rarifica a partir de la sexta centuria.

- Tipo D: cuencos con perfiles carenados y sinuosos, algunos con doble carena.

- Tipo E: cuenco hemisférico sin carena o con carena apenas insinuada.

Si bien los cuencos carenados se mantienen hasta mediados del siglo VIII, poco a poco van desapareciendo en favor de formas mucho más redondeadas sin presencia de carena que, en cualquier caso, se hace especialmente sutil.

Una forma que no permanece en el registro más allá de mediados de la sexta centuria son las copas, como ya afirmara A. Vigil-Escalera en otro trabajo (2013). Los contextos más tardíos en los que aparecen formas tipo copas en la cuenca del Duero serían El Pelambre y la fase más temprana de Canto Blanco, así como en contextos como El Castillón o Castro Ventosa, datados entre los siglos V y VI d. n. e. En general, lo que se produce es una progresiva desaparición de los pies y de los fondos anulares o resaltados. Mientras que en contextos de la segunda mitad de la quinta centuria y primera mitad de la sexta este tipo de fondos son relativamente frecuentes (por ejemplo, en Cárcava de la Peladera, donde son especialmente abundantes), en los contextos de la segunda mitad del siglo sexto o séptimo desaparecen casi de forma completa, sustituidos por fondos planos, muchos conservando un umbo muy desarrollado y, a partir de la séptima centuria, fondos con cierto perfil cóncavo.

En cuanto a las formas abiertas tipo plato se pueden detectar procesos similares a los documentados en los cuencos (Fig. 9). En general, se produce una simplificación progresiva de las formas, con labios cada vez menos desarrollados y que cada vez reciben menos decoración en los bordes y en su interior, bastante comunes hasta mediados de la sexta centuria. Una forma relativamente recurrente hasta mediados del siglo VI d. n. e. son las derivadas de la tipo Rigoir $3 \mathrm{~b}$, con los bordes recortados en forma de estrella, pero que no superan la primera mitad de la sexta centuria, en contextos como
Castro Ventosa. Es a partir de mediados del siglo VI d. n. e. y ya durante toda la séptima centuria cuando se observa la aparición de los perfiles carenados, contemporáneamente a los cuencos. Si bien este tipo de formas abiertas se presentan en toda la secuencia, lo que se observa es una progresiva disminución de su representación cuantitativa dentro de los conjuntos, siendo prácticamente marginales a partir de mediados de la séptima centuria. Así, en los contextos cerámicos con un número significativo de fragmentos inventariados, las formas tipo platos son prácticamente inexistentes. Únicamente en La Mata del Palomar se detecta un número significativo de estas (11\% del total de formas) y en Ladera de los Prados aparece en un $7 \%$, no localizándose ninguna forma reconocible o un conjunto mínimamente significativo en yacimientos como Senovilla, La Huesa o El Ventorro.

En cambio, se mantienen en toda la secuencia otros tipos de formas abiertas, tipo barreño o fuente, aunque su importancia cuantitativa en los contextos nunca es muy alta. Las formas que presentan son muy similares a lo largo de toda la secuencia, si bien el cambio más significativo es su producción mayoritaria mediante sistemas de rotación lenta a partir de mediados de la sexta centuria. Así mismo, existe una tendencia visible hacia los perfiles más redondeados y menos angulosos.

También se mantienen de forma muy minoritaria en los contextos las tapaderas (Fig. 10). En todo el repertorio cerámico analizado no se han documentado más de una veintena de estas formas, y ninguna dentro de la última etapa de la secuencia trabajada, seguramente sustituida por otro tipo de materiales, como la madera (Fournier 1982). Lo más significativo de esta morfología es, por un lado, la simplificación de las formas desde mediados de la quinta centuria, momento en el que se localizan algunas como la 31 de Rigoir. A partir de la sexta centuria se simplifican las propias formas, pero manteniendo decoraciones estampilladas. Por otro lado, se destaca que, a pesar de la simplificación formal, siguen recibiendo decoraciones relativamente complejas a modo, sobre todo, de incisiones.

Sin duda, el grueso de las producciones en los contextos rurales altomedievales son las formas cerradas, que representarían más del $80 \%$ de prácticamente todos los conjuntos. Como ya se indicara, entre las formas cerradas existe una amplia variedad en los contextos del centro peninsular, que incluirían formas de bol, cántaro, tinaja, botella y orza (Larrén et alii 2003). Lo interesante de estas formas es que tienen su momento de mayor apogeo hasta mediados del siglo VI d. n. e., conservándose solo algunas de ellas hasta finales de esa centuria. A partir del siglo VII d. n. e. prácticamente todas ellas desaparecen de los contextos en favor de las ollas de perfiles globulares y algu- 


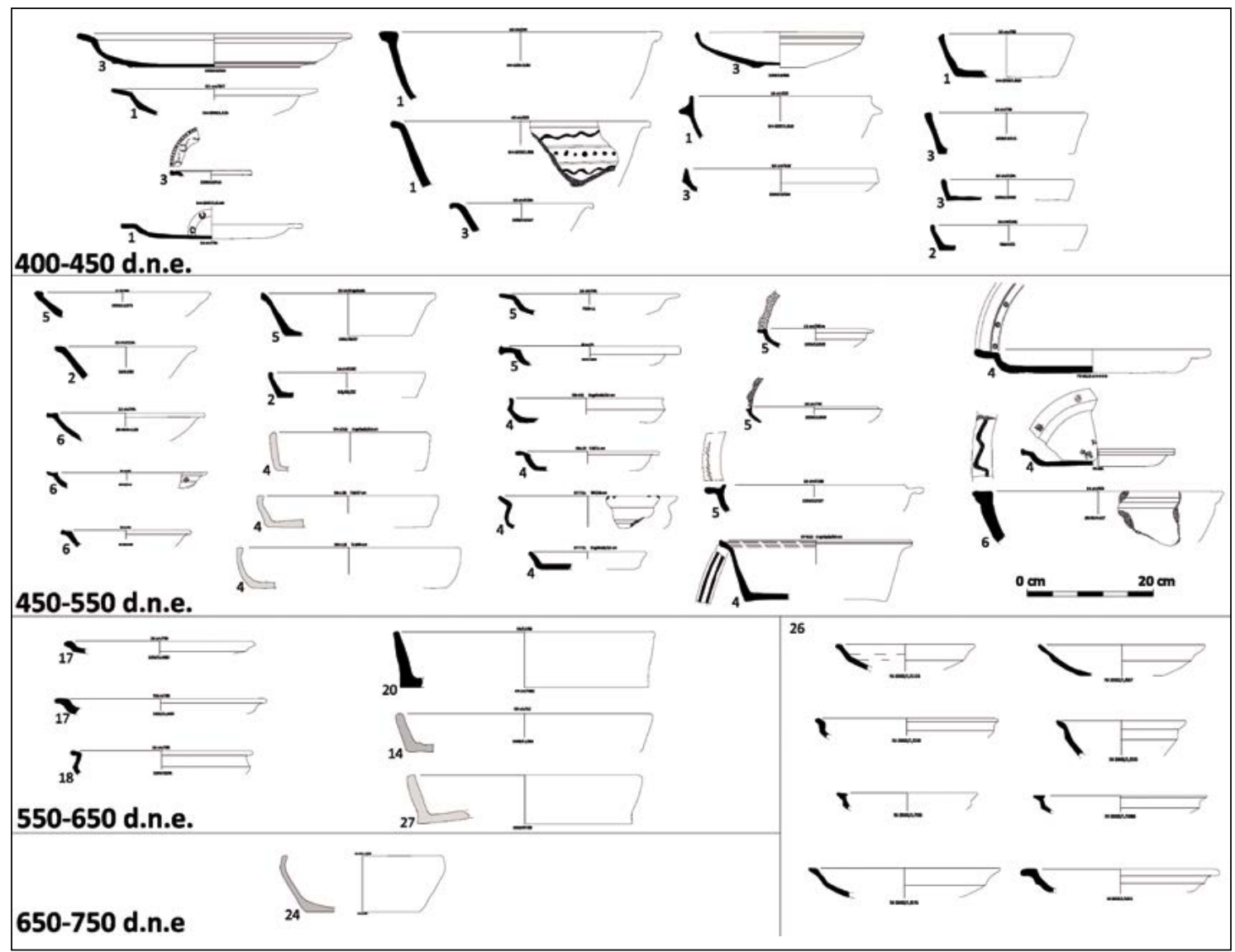

Figura 9. Propuesta de secuencia para las formas abiertas tipo plato, fuente y barreño. 1. Carratejera; 2. Villanueva de Azoague; 3. Villafilar; 4. Viladonga; 5. Castro Ventosa; 6. Cárcava de la Peladera; 14. Santovenia; 17. Ladera de los Prados; 18. Navamboal; 24. Los Cepones; 26. La Mata del Palomar (elaboración propia).

nos ejemplares de jarras y, de forma muy escasa, botellas. Así mismo, cabe mencionar la aparición, al menos hasta mediados de la sexta centuria y concentrados sobre todo en los yacimientos de Castro Ventosa y Viladonga, de vasitos, la mayoría derivados de la forma V2 definida por Alcorta y Bartolomé para el entorno de la ciudad de Lugo (Alcorta Irastorza y Bartolomé Abraira 2012; Tejerizo García et alii 2019)

No hay duda de que en términos cuantitativos, la mayoría de formas cerradas parecen corresponder con formas tipo olla, que presentan "una proliferación en todos los yacimientos" así como una gran "amplitud cronológica" (Larrén et alii 2003: 295) (Fig. 11). Si bien existen las lógicas variedades morfológicas, el tipo-ideal de olla podría describirse como un recipiente de formato globular con fondo plano o ligeramente cóncavo con borde exvasado, redondeado y ligeramente engrosado y con boca entre los $12-16 \mathrm{~cm}$ en la mayoría de los casos, de la que puede salir un asa del borde, generalmente anular o de cinta de reducido tamaño (menos de $2 \mathrm{~cm}$ ) con o sin depresión central o con dos líneas incisas paralelas. En multitud de ocasiones las ollas reciben una decoración en forma de líneas incisas o en onda en la parte superior del cuerpo, normalmente en la zona del hombro. Un aspecto destacable de esta forma es que a medida que avanza el período aquí estudiado los formatos globulares se van ampliando, a la vez que se achatan las formas, generando ollas de panzas muy globulares que serán características de los contextos de finales de la séptima y la octava centuria, como ocurre al sur del sistema central (Vigil-Escalera 2007a). Así mismo, los bordes son cada vez menos exvasados, generando perfiles de bordes rectos en muchas ocasiones. Ambas características pueden ser consecuencia de la progresiva aparición de la producción mediante rotaciones discontinuas dado que estas formas son más fáciles de realizar bajo esta técnica. 


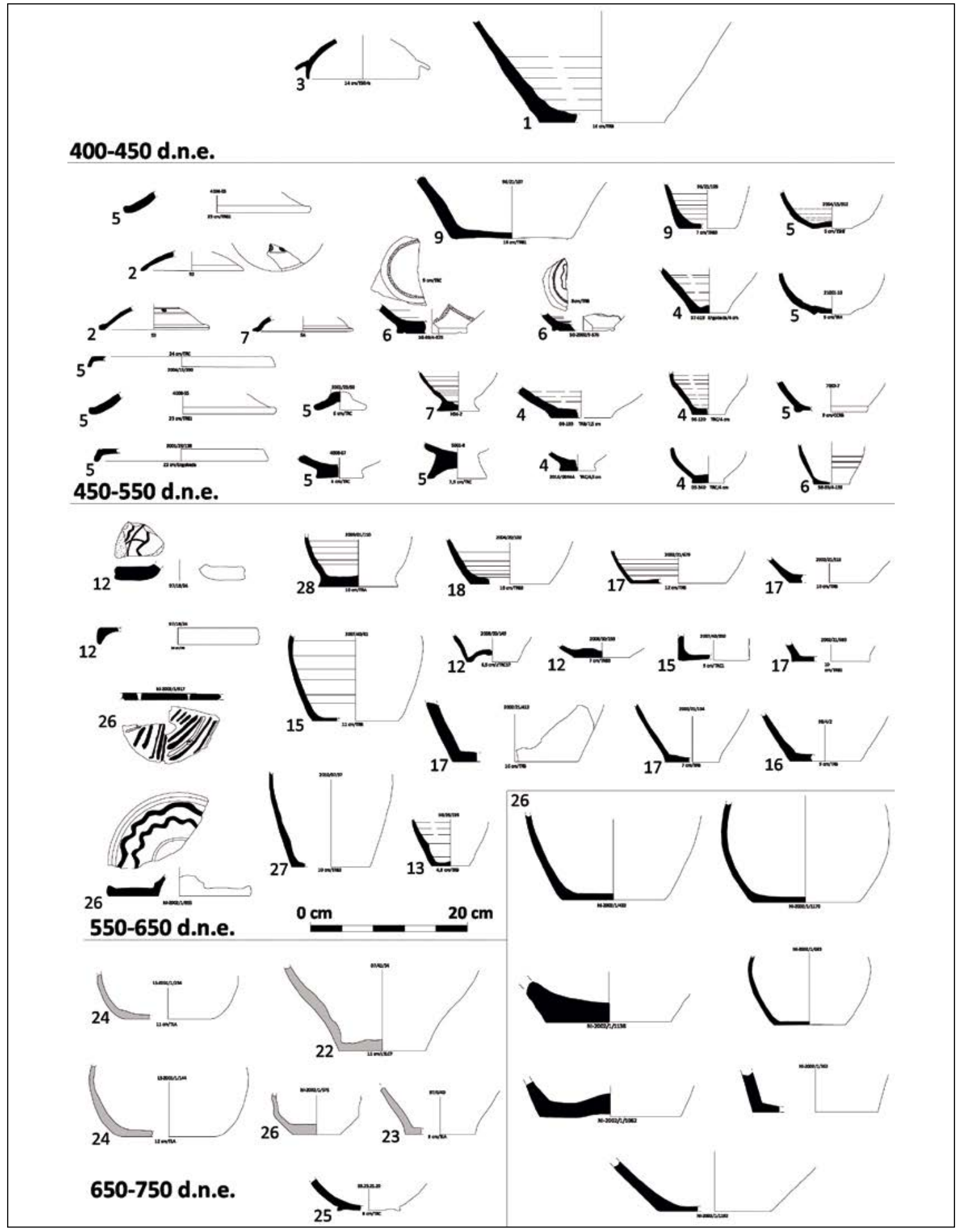

Figura 10. Propuesta de secuencia para las tapaderas y los fondos. 1. Carratejera; 2. Villanueva de Azoague; 3. Villafilar; 4. Viladonga; 5. Castro Ventosa; 6. Cárcava de la Peladera; 7. El Pelambre; 9. El Cementerio/Camino de Pedrosa; 12. El Cañal; 13. Tordillos; 15.Senovilla; 16. Rubí de Bracamonte; 17. Ladera de los Prados; 18.Navamboal; 22. Las Hiruelas; 23. La Huesa; 24. Los Cepones; 25. El Ventorro; 26. La Mata del Palomar (elaboración propia). 


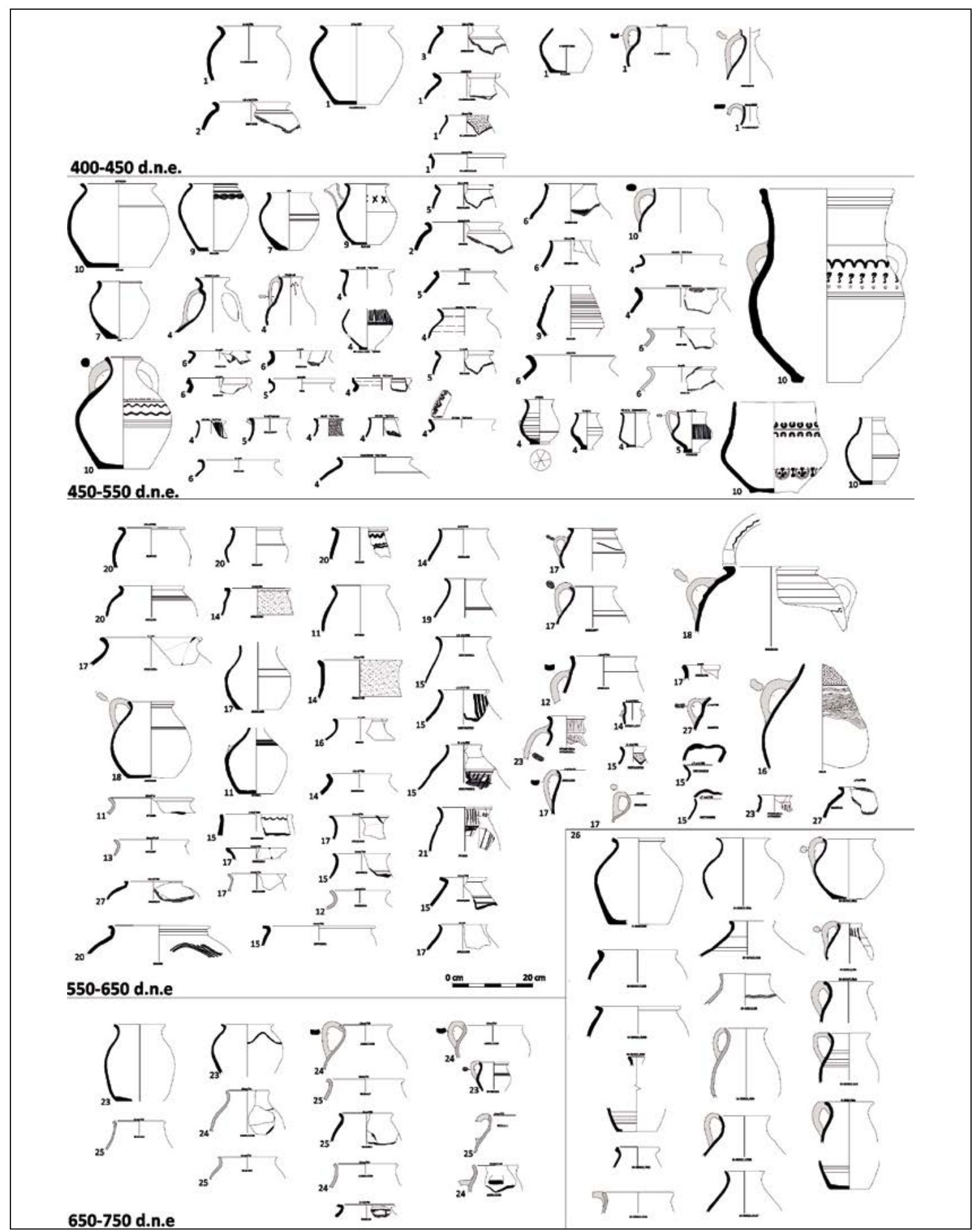

Figura 11. Propuesta de secuencia para las principales formas cerradas. 1. Carratejera; 2. Villanueva de Azoague; 3 . Villafilar; 4. Viladonga; 5. Castro Ventosa; 6. Cárcava de la Peladera; 7. El Pelambre; 8. El Castillón; 9. El Cementerio/Camino de Pedrosa; 10.Navasangil; 11. El Cementerio (Langayo); 12. El Cañal; 13. Tordillos; 14. Santovenia; 15.Senovilla; 16. Rubí de Bracamonte; 17. Ladera de los Prados; 18.Navamboal; 19. Vega de Duero; 20.Escorralizas; 21. Valdecelada/Los Torbisqueros; 22. Las Hiruelas; 23. La Huesa; 24. Los Cepones; 25. El Ventorro; 26. La Mata del Palomar; 27. Gallegos (elaboración propia). 
La diferenciación de las diversas modalidades de jarra (jarro, jarra, jarrito y jarrita) no es una tarea sencilla dado el nivel de fragmentación de la cerámica analizada. Sin embargo, algunas características podrían indicar la presencia de formas destinadas mayoritariamente a la contención de líquidos, que sería su característica funcional diferenciadora. Así, cacharros con formas alargadas y cuellos muy desarrollados con bocas ligeramente estrechas $(10-12 \mathrm{~cm})$ y presencia de una o dos asas podrían indicar este tipo de formas. Estas serían relativamente comunes en el registro y una característica es que desarrollan decoraciones complejas y reciben los mejores tratamientos tecnológicos (muchas de ellas asociadas a la cadena TRA, definida precisamente por su buena depuración). Algunas formas particulares presentan molduras y resaltes en los perfiles, que en ocasiones son especialmente desarrollados. Junto con los cuencos, es una forma que aparece frecuentemente carenada. Algunas formas llaman especialmente la atención, como son los contenedores de líquido que presentan bocas especialmente estrechas en relación con los cuerpos (como se localizan en Senovilla o La Mata del Palomar, por ejemplo). Otra forma particular sería la jarra con vertedero lateral, ya reconocida anteriormente, y documentada por ejemplo en Cementerio-Camino de Pedrosa (Larrén et alii 2003: 296). A medida que avanza el período parece disminuir su importancia en el registro, si bien nunca llegan a desaparecer de forma completa.

Algo similar ocurre con las formas tipo botella. $\mathrm{Si}$ bien no varían en exceso a lo largo del período, siendo la mayoría biansadas con el asa partiendo de la zona central del cuello, sí que se documenta una disminución cuantitativa a medida que avanza el período. Sin embargo, esto no quiere decir que dejen de ser utilizadas y producidas. No hay que olvidar la enorme frecuencia de botellas en los contextos funerarios tardíos de la sexta y séptima centuria (Carmona Berenguer 1991). De hecho, una de las cadenas tipológicas documentadas, la denominada como TRC1, caracterizada por una buena depuración, por la presencia de cocciones mayoritariamente oxidantes, así como por algunos fondos de formato troncocónico se podrían relacionar con este tipo de botellas, lo que podría ser un indicador de una frecuencia relativa alta dentro de los contextos.

Por último, cabe hacer mención a las ollas de gran formato o grandes contenedores, destinadas al almacenamiento cotidiano, y realizadas, por su gran tamaño, a mano mediante el sistema de colombinos (Fig. 12). Se trata de una forma cerámica que sufre pocas modificaciones entre los siglos V y VII, presentando un reducido número de formas, normal- mente en formatos globulares, entre las que destacan aquellas con bordes invasados y moldura bajo el labio y también otras con bordes en " $T$ " y bordes rectos. Muchas de estas formas reciben decoraciones en la parte superior del cuerpo en forma de cordones o digitaciones o líneas onduladas irregulares, que se irán rarificando con el paso del tiempo. Un proceso generalizado a partir de la quinta centuria, pero muy significativo a partir de la séptima centuria es la reducción de los tamaños de estos contenedores, sobre todo si se ponen en comparación con las dolia romanas. Mientras que aquellas podían llegar a los $40 \mathrm{o}$ $50 \mathrm{~cm}$ de ancho de boca, los grandes contenedores a partir de la sexta centuria apenas sobrepasan los 30 $\mathrm{cm}$, si bien hay excepciones. Este proceso de reducción de los tamaños de los grandes contenedores o de las ollas de gran formato habría que ponerlo en relación con el abandono progresivo de los sistemas de almacenamiento mediante dolia, sustituidos a partir de la quinta y sexta centuria por los silos de almacenamiento. Asimismo, a partir del siglo VII parece producirse una estandarización de las formas de estas grandes ollas en torno a formatos globulares con bordes rectos y aplanados.

\section{REGIONALIZACIÓN PRODUCTIVA}

Uno de los aspectos más significativos de las producciones cerámicas de época altomedieval, sobre todo después de la quinta centuria, es su evidente variación regional; cuestión que se pone cada vez más de relieve cuando se comparan distintos territorios (Vigil-Escalera y Quirós Castillo 2016). El análisis de un número muy significativo de cerámicas de yacimientos tan diversos como el que aquí se presenta ha permitido observar algunas de estas variaciones productivas regionales. Aquí solo apuntaremos algunas de las más relevantes a la espera de estudios y análisis de detalle que permitan profundizar en este tema, evidente pero falto de estudios específicos.

El repertorio formal es, sin duda, uno de los principales indicadores para detectar producciones territoriales, ya utilizadas para diferenciar otros grandes conjuntos cerámicos, como los prehistóricos (González-Ruibal 2006-2007). Igualmente, las variables tecnológicas y de composición de las cerámicas pueden ofrecer algunas primeras observaciones que, sin duda, deberán ser contrastadas y profundizadas mediante análisis arqueométricos más específicos (Centeno Cea y Villanueva Zubizarreta 2018; Grassi y Quirós Castillo 2018). Prestando atención a estos elementos, se han podido distinguir hasta cinco potenciales producciones y ámbitos de distribución regionales. 


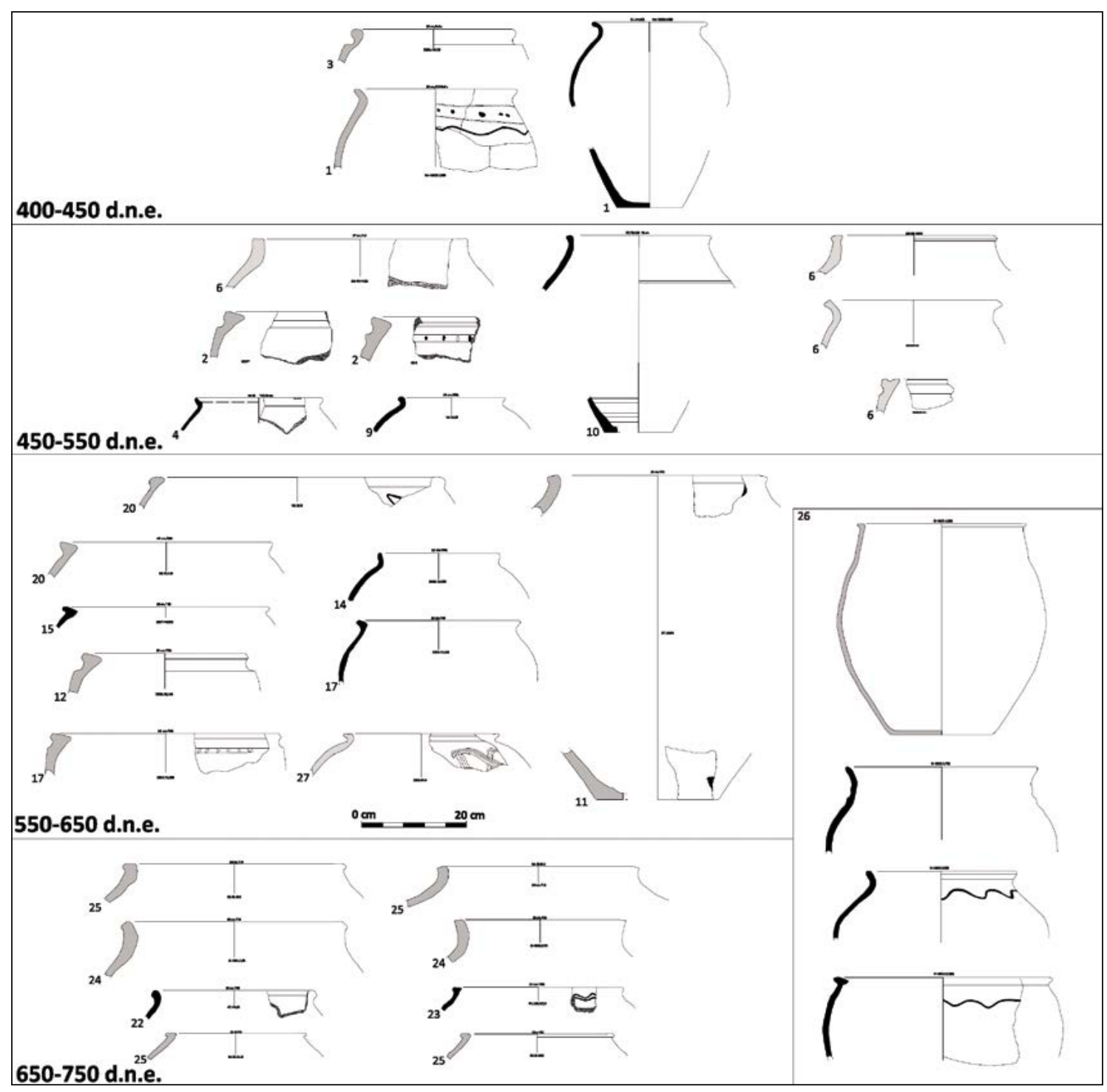

Figura 12. Propuesta de secuencia para las principales formas cerradas de gran formato. 1. Carratejera; 2. Villanueva de Azoague; 3. Villafilar; 4. Viladonga; 6. Cárcava de la Peladera; 9. El Cementerio/Camino de Pedrosa; 10.Navasangil; 11. El Cementerio (Langayo); 12. El Cañal; 14. Santovenia; 15.Senovilla; 17. Ladera de los Prados; 20.Escorralizas; 22. Las Hiruelas; 23. La Huesa; 24. Los Cepones; 25. El Ventorro; 26=La Mata del Palomar; 27. Gallegos (elaboración propia).

Una de las más evidentes es la diferencia entre los contextos del noroeste peninsular (región I) con respecto a los de la meseta central, sobre todo atestiguados en los yacimientos de Castro Ventosa y de Viladonga, ambos asentamientos fortificados en altura datados entre el siglo $\mathrm{V}$ y mediados del VI d. n. e. Estas diferencias, sin embargo, parecen extenderse a otros contextos similares de la zona datados en momentos posteriores (Alcorta Irastorza y Bartolomé Abraira 2012; Fernández Fernández y Bartolomé
Abraira 2016). Las principales diferencias se reflejan fundamentalmente en el aparato decorativo y formal. En cuanto a este último ya se hizo referencia a la presencia de los vasitos en estos contextos que no aparecen en el centro peninsular y que podrían ser una producción lucense con una distribución regional (Alcorta Irastorza y Bartolomé Abraira 2012). Decorativamente, frente a la hegemonía de la decoración estampillada en contextos del centro peninsular hasta mediados de la sexta centuria, en el noroeste se susti- 
tuyen principalmente por las incisiones y los bruñidos. Esto se observa de forma clara en el aparato decorativo de los platos y cuencos, que en sitios como Navasangil o El Castillón muestran una preferencia por el estampillado frente a las líneas bruñidas de contextos como Viladonga (Tejerizo García et alii 2018), aspecto que parece extenderse a todo el contexto noroccidental (Fernández Fernández y Bartolomé Abraira 2016).

Por su parte, en el sector noroccidental de la cuenca del Duero (región II) se observa la presencia de un tipo de decoración facetada que consiste en el corte a cuchillo de la parte inferior de producciones carenadas cuando la pasta está todavía fresca, de manera que se produce una superficie con múltiples caras planas. Este tipo de decoración se reconoció inicialmente en el yacimiento de El Pelambre (Pérez Rodríguez-Aragón y González Fernández 2010) pero también se ha podido documentar en los sitios de Canto Blanco, Gallegos y en El Castillón (Sastre Blanco et alii 2018: 392). Esto mostraría un tipo de decoración regionali- zada, si bien de taller original desconocido, y que se puede datar, esencialmente, en la primera mitad del siglo VI d. n. e. (Fig. 13).

Como ya se ha mencionado, a mediados de la sexta centuria se produce una transformación del tipo de decoraciones utilizadas, desde el uso del molde y el estampillado, hacia una hegemonía de las incisiones y los bruñidos. Estos, en ocasiones, se combinan, generando formas decorativas muy elaboradas de rejillas de bruñidos e incisiones. Si bien esta decoración parece estar presente en numerosos contextos, sobre todo en aquellos datados entre la segunda mitad del VI y principios del VII d. n. e., parece concentrarse de forma significativa en contextos situados en el centroeste de la cuenca del Duero (región III). En este sentido, destacan los aparatos decorativos de yacimientos como Senovilla, Ladera de los Prados, Navamboal o La Mata del Palomar, sugiriendo un taller regional caracterizado por estas decoraciones.

Uno de los aspectos más significativos de la secuencia cerámica de época altomedieval es que, ya

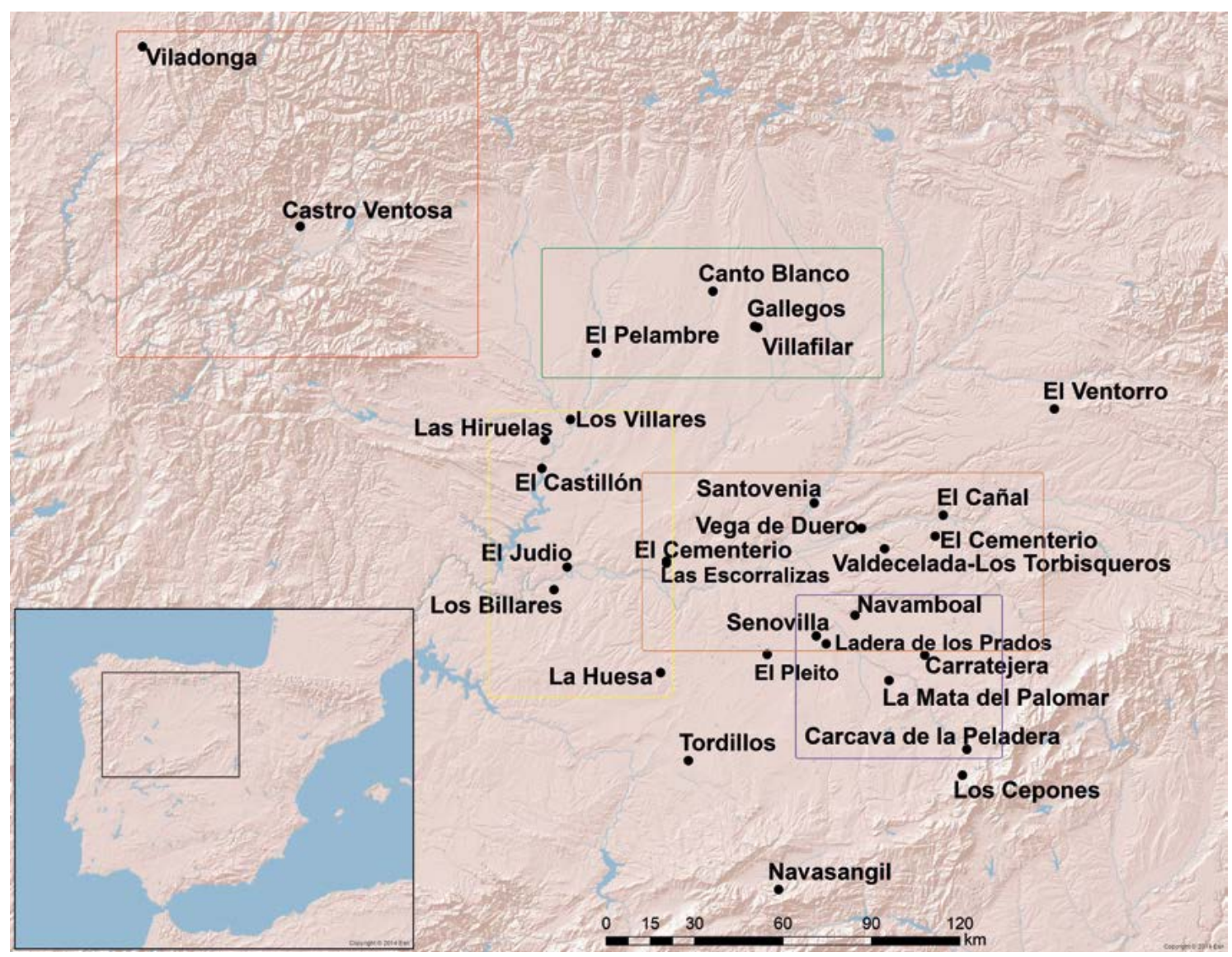

Figura 13. Regionalizaciones productivas de cerámica en el centro y noroeste peninsular (elaboración propia). 
desde finales de la quinta centuria, se va imponiendo en los contextos la cadena definida como TRB, caracterizada por las cocciones reductoras, el uso de tecnologías que permiten una rotación más continuada y la escasa depuración. La importancia cuantitativa de esta cadena tecnológica dentro de los contextos permite detectar numerosas variantes productivas que, en último término, podrían estar respondiendo a variedades regionales de producción cerámica. Así, dos potenciales variantes que aparecen con cierta asiduidad en los conjuntos son aquellas denominadas como TRB2 y TRB3. En cuanto a la primera, se trata de una cerámica caracterizada por su producción mediante rotaciones muy continuas (con huellas muy claras de rotación en el interior de los cacharros), cocción irregular tendente a oxidante con pastas micáceas con depuraciones medias y presencia de alisados exteriores cuidados. Se trata de características técnicas que acercan este tipo de producciones a los ciclos de "cerámica común romana" y con la que parecen compartir evidentes similitudes. Esta cadena ha sido detectada principalmente en contextos situados en la parte norte y este de la cuenca del Duero (región IV), como en Gallegos ( $25 \%$ del total de fragmentos), El Cementerio-Camino de Pedrosa (17,4 \%), Las EscorralizasCamino de Quiñones (13\%) o Las Hiruelas (25\%), pudiendo mostrar un cierto patrón de distribución regional. Algo similar ocurre con la cadena TRB3, muy similar a lo descrito para la TRB pero caracterizada por las cocciones mixtas, que dejan un corte "tipo sándwich" con pastas pardas al interior y grises/ negras al exterior. Si bien este tipo de producciones se han detectado en numerosos contextos, su máxima concentración se produce en el centro y centro-oeste de la cuenca del Duero, en yacimientos como Navamboal (35,5\% del total de fragmentos), Senovilla (14,5 $\%)$ o La Huesa $(14,4 \%)$.

Mención aparte merece la cadena tecnológica definida como TRB1, caracterizada por la presencia de pastas micáceas/graníticas, las cocciones reductoras y depuraciones bajas y ya reconocida en otras publicaciones como vinculada al entorno granítico del occidente de la meseta (región V) (Centeno Cea y Villanueva Zubizarreta 2018). Sus características técnicas hacen muy complicada la diferenciación de la técnica de modelado; si bien en muchas ocasiones las líneas del torneado aparecen de forma clara, en otras muestran todas las características de un sistema de producción mediante rotaciones discontinuas. Lo más probable es que con este tipo de pastas con inclusiones graníticas se combinen ambas formas de producción y que, por lo tanto, haya producciones a torno rápido y también a torno lento. Esto explicaría, por ejemplo, que, en sitios como El Pelambre, con una alta propor- ción de esta CTO, no se hayan detectado producciones a torno lento. Se trata de una cadena tecnológica cuyas características principales pueden asimilarse con el grueso de conjuntos de períodos anteriores, como en El Castillón o El Cristo de San Esteban pero que tienen un amplio grado de difusión a partir de la sexta y séptima centuria. Así, esta cadena tecnológica está presente en prácticamente todos los conjuntos analizados en el presente trabajo en proporciones entre el $1 \%$ (El Ventorro) hasta el 61,7 \% (El Pelambre).

\section{CONSIDERACIONES FINALES}

Las últimas dos décadas han supuesto un vuelco en la forma de entender las sociedades altomedievales septentrionales de la península ibérica a partir del registro material. Esto ha sido posible fundamentalmente por la incorporación a las investigaciones de una ingente cantidad de datos provenientes tanto de programas de investigación como de las intervenciones vinculadas a la arqueología comercial. Sin embargo, solo poco a poco, se está logrando sistematizar toda esta información para la producción de narrativas arqueológicas coherentes sobre este período (Martínez Jiménez et alii 2018). Uno de los grandes obstáculos para resolver esta cuestión ha sido la propia datación de los contextos, determinada en gran medida por la ausencia de secuencias cerámicas que permitieran, al menos, una primera aproximación cronológica a los contextos altomedievales. Si bien este problema iba encontrando ciertas soluciones para los contextos de la quinta y sexta centuria en el centro y noroeste peninsular, se volvía prácticamente irresoluble para los contextos entre la sexta y la octava centuria. Así, el principal objetivo de este trabajo fue, a partir de un análisis de conjunto de una amplia variedad de yacimientos relativamente bien datados, proporcionar un acercamiento en términos de secuencia cronológica a la cerámica del territorio al norte del Sistema Central. De esta manera, se pretendía dotar de una herramienta heurística, así como analítica para abordar estos contextos.

Del mismo modo, un análisis de tipo tecnológico, formal y regional permite definir con mayor claridad las profundas transformaciones operadas en las sociedades peninsulares tras la desintegración del Imperio Romano. El tipo de producciones cerámicas, como una parte integrante de la economía política de las sociedades altomedievales, viene determinado por el tipo de sociedades que las producen. Así, las transformaciones observadas en los repertorios cerámicos, tanto en sus procesos de producción, distribución y consumo, son una consecuencia de los fenómenos 
sociales y políticos más generales ocurridos en este período. El abandono de las villas tardoimperiales, la reocupación de asentamientos fortificados en el norte peninsular y la emergencia de sociedades de tipo campesino que pueblan los paisajes rurales (Tejerizo García 2016b; Vigil-Escalera 2015) son los principales acontecimientos visibilizados arqueológicamente que contextualizan y explican las transformaciones documentadas en los repertorios cerámicos.

Son estas conexiones entre las cadenas tecnológicas, las estructuras económicas y los procesos sociales las que, en términos arqueológicos, deben guiar los estudios cerámicos en el futuro. Para ello será fundamental contrastar, matizar y corregir las secuenciaciones aquí propuestas de forma que sean herramientas útiles, no solo para la datación de los contextos arqueológicos, sino para analizar con mayor profundidad las sociedades productoras de las cerámicas. Para ello será fundamental avanzar en la aplicación de métodos de datación radiométrica, que permitan aquilatar con mayor precisión los repertorios cerámicos excavados estratigráficamente. Así mismo, un interesante camino que aquí se abre es el del análisis pormenorizado de las variaciones regionales en la producción cerámica, que viene determinado no solo por el método comparativo en yacimientos conocidos o por conocer, sino por la aplicación de métodos arqueométricos más sólidos (Ariño et alii 2005; Dahí Elena 2012; Grassi y Quirós Castillo 2018). En cualquier caso, este es un paso más en un largo camino por recorrer.

\section{AGRADECIMIENTOS}

Este trabajo ha sido realizado en el marco del proyecto Agencia campesina y complejidad sociopolítica en el noroeste de la Península Ibérica en época medieval (Ministerio de Economía, Industria y Competitividad, HUM2016-76094-C4-2-R), el Grupo de Investigación en Patrimonio y Paisajes Culturales (Gobierno Vasco, IT936-16) y el Grupo de Estudios Rurales (Unidad Asociada UPV/EHU-CSIC) dirigidos por Juan Antonio Quirós Castillo y gracias a una beca de investigación postdoctoral financiada por la Xunta de Galicia. Quedo especialmente agradecido a las empresas Strato y Aratikos que facilitaron el acceso a todas las intervenciones que forman parte de este trabajo. Igualmente agradezco a todas las trabajadoras y trabajadores de los museos donde se realizó el trabajo de análisis. A Alfonso VigilEscalera y a Juan Antonio Quirós Castillo por la revisión del texto y los continuos consejos para llevarlo a buen puerto y a Clara Hernando Álvarez, por su paciencia al revisar el trabajo. También quedo agradecido a la evaluación externa y al comité editorial de la revista; cualquier error en este sentido, es obra exclusiva del autor.

\section{BIBLIOGRAFÍA}

Abascal Palazón, J. M. 1986: La cerámica pintada romana de tradición indígena en la Península Ibérica. Centros de producción, comercio y tipología, Alicante.

Alba, M., y Gutiérrez Lloret, S. 2008: "Las producciones de transición al Mundo Islámico: el problema de la cerámica paleoandalusí (siglos VIII y IX)", D. Bernal Casasola y A. Ribera I Lacomba (eds.), Cerámicas hispanorromanas: un estado de la cuestión, Cádiz, 585-613.

Alcorta Irastorza, E. J., y Bartolomé Abraira, R. 2012: "Muestras de cerámica engobada romana de producción local de Lucus Augusti (Lugo)”, D. Bernal Casasola y A. Ribera i Lacomba (eds.), Cerámicas hispanorromanas II. Producciones regionales, Cádiz, 699-724.

Amorós Ruiz, V. 2018: El Tolmo de Minateda en la Alta Edad Media. Cerámica y contexto, Alicante.

Aquilué Abadías, X. 2003: "Estado actual de la investigación de la Terra Sigillata Africana en la Península Ibérica en los siglos VI-VII", L. Caballero Zoreda, P. Mateos y M. Retuerce (eds.), Cerámicas tardorromanas y altomedievales en la Península Ibérica, Anejos Archivo Español de Arqueología XXVIII, Madrid, 11-20.

Aranda González, R. 2014: "Cerámica de época visigoda: una historia de la investigación", Anales de Prehistoria y Arqueología de Murcia 30: 107-131.

Ariño, E., Barbero, L. y Suárez Barrios, M. 2005: "Primeros datos sobre análisis arqueométricos de la cerámica de cocina del período romano tardío/ visigodo de la provincia de Salamanca (España)", J. M. Gurt i Esparraguera, J. Buxeda i Garrigós y M. A. Cau Ontiveros (eds.), LRCW I. Late Roman Coarse Wares, Cooking Wares and Amphorae in the Mediterranean, BAR, Oxford, 69-79.

Bohigas Roldán, R., Andrio Gonzalo, J., Peñil Mínguez, J. y García Alonso, M. 1989: "Las cerámicas medievales no esmaltadas en las provincias de Cantabria, Palencia y Burgos”, R. Bohigas Roldán y J. A. Gutiérrez González (eds.), La cerámica medieval en el norte y noroeste de la Península Ibérica, León, 113-153.

Bustamante Álvarez, M. 2016: "La cerámica pintada romana de tradición indígena en el territorio de Extremadura", SPAL 25, 183-207. 
Caballero Zoreda, L. 1972: "Cerámica sigillata gris y anaranjada paleocristiana en España", Trabajos de Prehistoria 29, 189-218.

Caballero Zoreda, L. y Argente Oliver, I. 1975: “Cerámica paleocristiana, gris y anaranjada, producida en España”, Trabajos de Prehistoria 32 (1), 113-150.

Caballero Zoreda, L., Mateos Cruz, P. y Retuerce, M. 2003: Cerámicas tardorromanas y altomedievales en la Península Ibérica, Anejos Archivo Español de Arqueología XXVIII, Madrid.

Caballero Zoreda, L. y Megías Pérez, G. 1977: “Informe de las excavaciones del poblado medieval del Cancho del Confesionario, Manzanares el Real (Madrid)", Noticiario Arqueológico Hispánico 5, 325-331.

Carmona Berenguer, S. 1991: "Estudio tipológico de la cerámica funeraria de la necrópolis de El Ruego (Almedinilla, Córdoba)", Anales de arqueología cordobesa 2, 371-394.

Centeno Cea, M. I., Palomino, Á. L. y Villadangos, L. M. 2010: "Contextos cerámicos de la primera mitad del s.V en el interior de la Meseta. El yacimiento de Las Lagunillas (Aldeamayor de San Martín, Valladolid)", Boletín del Seminario de Estudios de Arte y Arqueología LXXVI, 91-144.

Centeno Cea, M. I. y Villanueva Zubizarreta, O. 2018: "La cerámica en la Cuenca del Duero: estudio tecnológico y arqueométrico", F. Grassi y J. A. Quirós Castillo (eds.), Arqueometría de los materiales cerámicos de época medieval en España, Documentos de Arqueología Medieval 12, Bilbao, 163 178.

Comas i Solà, M., Gurt i Esparraguera, J. M., López Mullor, A., Padros i Martí, P. y Roca i Roumens, M. 1997: Contextos ceràmics d'época romana tardana i de l'alta edad mitjana (segles $I V-X)$, Barcelona.

Dahí Elena, S. 2012: Contextos cerámicos de la Antigüedad Tardía y la Alta Edad Media (siglos IVVIII d.C) en los asentamientos rurales de la Lusitania Septentrional (Provincia de Salamanca), British Archaeological Reports, Oxford.

Estremera, S., Centeno Cea, M. I. y Quintana, J. 2006: Arqueología urbana en Ávila: La intervención en los solares del Palacio de Don Gaspar del Águila y Bracamonte, Junta de Castilla y León, Valladolid.

Fernández Fernández, A. 2014: El comercio tardoantiguo (ss. IV-VII) en el Noroeste peninsular a través del registro cerámico de la ría de Vigo, Archaeopress, Oxford.

Fernández Fernández, A. y Bartolomé Abraira, R. 2016: "Cerámicas tardoantiguas en el noroeste de la Península (Galicia y norte de Portugal): entre la importación y el artesanado local/regional", J. A. Quirós Castillo y A. Vigil-Escalera (eds.), Bilbao, 69-111.

Fournier, G. 1982: «Usages et techniques de la vie quotidienne: vaisselle des bois, silos» Mélanges d'archéologie et d'histoire médiévales en l'honneur du Doyen Michel de Bouärd, 155-169.

González-Ruibal, A. 2006-2007: Galaicos. Poder y comunidad en el Noroeste de la Península Ibérica (1200 a.C-50 d.C), Brigantium: Boletín do Museu Arqueolóxico e Histórico da Coruña 18, A Coruña.

Gozalo Viejo, F., Gonzalo González, J. M. y Blanco García, J. F. 2013: "El Cerro Tormejón (Armuña, Segovia). Análisis de sus materiales cerámicos tardoantiguos", Cuadernos de Prehistoria y Arqueología 39, 151-182.

Grassi, F. y Quirós Castillo, J. A. (eds.) 2018. Arqueometría de los materiales cerámicos de época medieval en España, Documentos de Arqueología Medieval 12, Bilbao.

Gutiérrez González, J. A. 2014: "Fortificaciones tardoantiguas y visigodas en el norte peninsular (ss. V-VIII)", R. Catalán Ramos, P. Fuentes Melgar y J. C. Sastre Blanco (eds.), Las fortificaciones en la tardoantigüedad. Élites y articulación del territorio (siglos V-VIII d.C.), Madrid, 191-214.

Juan Tovar, L. C. 2012a: "Las cerámicas imitación de sigillata (CIS) en la Meseta Norte durante el siglo V. Nuevos testimonios y precisiones cronológicas", C. Fernández Ibáñez y R. Bohigas Roldán (eds.), In durii regione romanitas. Homenaje a Javier Cortes, Santander/Palencia, 365-372.

Juan Tovar, L. C. 2012b: "Las cerámicas imitación de sigillata en el occidente de la Península Ibérica durante el siglo V d.C.", D. Bernal Casasola y A. Ribera i Lacomba (eds.), Cerámicas hispanorromanas II. Producciones regionales, Cádiz, 97-129.

Juan Tovar, L. C., Sanguino Vázquez, J., Oñate Baztán, P. y Penedo Cobo, E. 2013: "Hornos cerámicos bajoimperiales y tardoantiguos en el sur de la Comunidad de Madrid: presentación preliminar", Actas del I Congreso Internacional de la SECAH, 319-335.

Larrén, H., Villanueva Zubizarreta, O., Caballero, J., Domínguez Bolaños, A., Misiego Tejeda, J. C., Marcos, G. J., Blanco García, J. F., Sanz Huesma, F. J., Martín Montes, A., Nuño González, J. 2003: "Ensayo de sistematización de la cerámica tardoantigua en la cuenca del Duero", L. Caballero Zoreda, P. Mateos y M. Retuerce (eds.), Cerámicas tardorromanas y altomedievales en la Península Ibérica, Anejos de Archivo Español de Arqueología XXVIII, Madrid, 273-306. 
Lemonnier, P. 1992: Elements for an anthropology of Technology, University of Michigan, Michigan.

Lemonnier, P. 1993: “Introduction”, P. Lemonnier (ed.), Technological choices: transformation in material cultures since the Neolithic, London, 1-35.

León Asensio, C. y Barona Barona, M. 2013: "Terra Sigillata Africana D en la Meseta Norte", J. C. Sastre Blanco, R. Catalán Ramos y P. Fuentes Melgar (eds.), Arqueología en el valle del Duero. Actas de las primeras jornadas de jóvenes investigadores en el valle del Duero, Madrid, 291-298.

López Rodríguez, J. R. y Regueras Grande, F. 1987: "Cerámicas tardorromanas de Villanueva de Azoague (Zamora)", Boletín del Seminario de Estudios de Arte y Arqueología 53, 115-166.

Marín Suárez, C. 2012: "La cerámica de la Edad del Hierro en el sector centro-occidental cantábrico", Munibe 63, 165-198.

Martínez Jiménez, J., Sastre De Diego, I. y Tejerizo García, C. 2018: The Iberian Peninsula between 300. and 850. An archaeological perspective, Amsterdam.

Nozal Calvo, M. y Puertas Gutiérrez, F. 1996: La terra sigillata paleocristiana gris en la villa romana de la Olmeda. Valladolid.

Paz Peralta, J. A. 2013: “La vajilla de cerámica hispánica tardía gris y naranja en Asturica Augusta (Astorga, León). Conjunto C", Ex Officina Hispana. Cuadernos de la SECAH, 1, 217-256.

Pérez Rodríguez-Aragón, F. y González Fernández, M. L. 2010: "La cerámica de época hispanovisigoda de "El Pelambre" (Villaornate, León)", M. Crespo Díez y R. Martínez Peñín (eds.), Metodología de análisis aplicada a los estudios de cerámica tardoantigua y medieval de la Península Ibérica, León, 53-73.

Quirós Castillo, J. A. (ed.) 2013: El poblamiento rural de época visigoda en Hispania. Arqueología del campesinado en el interior peninsular, Documentos de Arqueología Medieval 6, Bilbao.

Sastre Blanco, J. C., Catalán Ramos, R. y Fuentes Melgar, P. 2014: "El conjunto cerámico de El Castillón (Zamora) y las cerámicas de imitación de Sigillata en el contexto del siglo V", R. Morais, A. Fernández y M. J. Sousa (eds.), As produçoes cerâmicas de imitaçao na Hispania, Porto, 537-547.

Sastre Blanco, J. C., Catalán Ramos, R., Fuentes Melgar, P., Vázquez Fadón, M., Rodríguez Monterrubio, Ó. y Álvarez Rodríguez, A. 2018: "Producciones cerámicas en el poblado de El Castillón entre los siglos V-VI d.C.”, I. Martín Viso, P. Fuentes Melgar, J. C. Sastre Blanco y R. Catalán Ramos (eds.), Cerámicas altomedievales en Hispania y su entorno (s.V-VIII), Madrid, 379-400.
Serrano Herrero, E., Torra Pérez, M., Catalán Ramos, R. y Vigil-Escalera Guirado, A. 2016: "La cerámica de los siglos VIII-IX en Madrid, Toledo y Guadalajara”, J. A. Quirós Castillo y A. Vigil-Escalera (eds.), La cerámica de la Alta Edad Media en el cuadrante de la Península Ibérica (siglos V-X). Sistemas de producción, mecanismos de distribución y patrones de consumo, Documentos de Arqueología Medieval 9, Bilbao, 279-314.

Tejerizo García, C. 2015: "Etnicidad, identidad y poder en la meseta norte durante la Edad Media: reflexiones desde la Arqueología”, J. A. Quirós Castillo y S. Castellanos (eds.), Identidad y etnicidad en Hispania. Propuestas teóricas y cultura material en los siglos V-VIII, Documentos de Arqueología Medieval 8, Bilbao, 221-238.

Tejerizo García, C. 2016a: "Construyendo la casa por los cimientos: consideraciones acerca de la cerámica de la primera Alta Edad Media en la parte central de la cuenca del Duero", J. A. Quirós Castillo y A. Vigil-Escalera (eds.), La cerámica de la Alta Edad Media en el cuadrante de la Península Ibérica (siglos V-X). Sistemas de producción, mecanismos de distribución y patrones de consumo, Documentos de Arqueología Medieval 9, Bilbao, 229-254.

Tejerizo García, C. 2016b: "The end of the world as we know it: post-imperial social lanscapes in North-Central Iberia (5th-6th centuries)", Archeologia Medievale XLIII, 383-397.

Tejerizo García, C. 2017a: Arqueología de las sociedades campesinas en la cuenca del Duero durante la Primera Alta Edad Media, Documentos de Arqueología Medieval 11, Bilbao.

Tejerizo García, C. 2017b: "Presencia de terra sigillata hispánica tardía meridional en contextos al norte del sistema central. La Cabeza de Navasangil", Boletín de la Sociedad de Estudios de la Cerámica Antigua en Hispania 8, 93-97.

Tejerizo García, C. 2018: “'Estampas del pasado'. Un análisis contextual del material estampillado en el mundo rural de la meseta norte (ss. V-VI d.C.)", I. Martín Viso, P. Fuentes Melgar, J. C. Sastre Blanco y R. Catalán Ramos (eds.), Cerámicas altomedievales en Hispania y su entorno (s.V-VIII), Madrid, 261-283.

Tejerizo García, C., Rodríguez González, C. y Fernández Pereiro, M. 2018: "Materiais cerámicos tardíos (ss. IV-VI d.C.) no castro de Viladonga", CROA. Boletín da Asociación de Amigos do Museo do Castro de Viladonga 28: 36-52.

Tejerizo García, C., Rodríguez González, C. y Fernández Pereiro, M. 2019: “¿Continuidad o discontinuidad en los castros del noroeste? Una revisión del 
yacimiento de Viladonga (Castro de Rei, Lugo)", SPAL 28.2, 279-313.

Vigil-Escalera, A. 2003: “Cerámicas tardorromanas y altomedievales de Madrid”, L. Caballero Zoreda, P. Mateos y M. Retuerce (eds.), Cerámicas tardorromanas y altomedievales en la Península Ibérica, Anejos de Archivo Español de Arqueología XXVIII, 371-387.

Vigil-Escalera, A. 2006: "La cerámica del período visigodo en Madrid", Zona arqueológica 8, 705716.

Vigil-Escalera, A. 2007a: "Algunas observaciones sobre las cerámicas "de época visigoda” (ss. V-IX d.C) de la región de Madrid", A. Malpica Cuello y J. C. Carvajal (eds.), Estudios de cerámica tardorromana y altomedieval, Granada, 359-382.

Vigil-Escalera, A. 2007b: "Granjas y aldeas altomedievales al norte de Toledo (450-800 d.C)", Archivo Español de Arqueología 80, 239-284.

Vigil-Escalera, A. 2013: "Las últimas producciones de TSHT en el interior peninsular", Ex officina hispania. Cuadernos de la SECAH 1, 11-24.

Vigil-Escalera, A. 2015: Los primeros paisajes altomedievales en el interior de Hispania. Registros campesinos del siglo quinto d.C., Documentos de Arqueología Medieval 7, Bilbao.
Vigil-Escalera, A. y Quirós Castillo, J. A. 2013: "Un ensayo de interpretación del registro arqueológico", J. A. Quirós Castillo (ed.), El poblamiento rural de época visigoda en Hispania. Arqueología del campesinado en el interior peninsular, Documentos de Arqueología Medieval 6, Bilbao.

Vigil-Escalera, A. y Quirós Castillo, J. A. 2016: La cerámica de la Alta Edad Media en el cuadrante noroeste de la Península Ibérica (siglos V-X), Documentos de Arqueología Medieval 9, Bilbao.

Vigil-Escalera, A. y Strato Gabinete de Estudios sobre Patrimonio Histórico y Arqueológico 2013: "El registro arqueológico del campesinado del interior peninsular en época altomedieval", J. A. Quirós Castillo (ed.), El poblamiento rural de época visigoda en Hispania. Arqueología del campesinado en el interior peninsular, Documentos de Arqueología Medieval, Bilbao, 289-328.

Recibido: 16-05-2019

Aceptado: 30-09-2019 
